\title{
Infrared Spectra and Photochemistry of Matrix-Isolated Pyrrole-2-carbaldehyde
}

\author{
Barbara Michela Giuliano,* Igor Reva, and Rui Fausto \\ Department of Chemistry, University of Coimbra, 3004-535 Coimbra, Portugal
}

Received: November 23, 2009; Revised Manuscript Received: January 13, 2010

\begin{abstract}
Monomeric pyrrole-2-carbaldehyde (P2C) was isolated in low-temperature argon and xenon matrices, and its UV-induced photochemistry was studied. The structures of the reagent as well as the reaction photoproducts were characterized by FTIR spectroscopy. Interpretation of the experimental results was assisted by theoretical calculations carried out at the MP2 and DFT (B3LYP) levels with the 6-311++G(d,p) basis set. The compound can assume two conformations, cis and trans, regarding the orientation of the $\mathrm{N}-\mathrm{C}-\mathrm{C}=\mathrm{O}$ dihedral angle. The cis form is the conformational ground state, being more stable than the trans by ca. $15 \mathrm{~kJ} \mathrm{~mol}^{-1}$. The relative stability of the two conformers was analyzed based on the comparison of their structures and using the natural bond orbital method. In agreement with the calculations, only the signature of the cis conformer was found in the experimental FTIR spectra of matrix-isolated P2C monomers. UV irradiation $(\lambda>235 \mathrm{~nm})$ readily converts the cis-P2C into the trans-P2C form, and a photostationary equilibrium is established where the [cis]/[trans] ratio is ca. 3.3:1 in both $\mathrm{Ar}$ and $\mathrm{Xe}$. Upon prolonged irradiation, P2C slowly undergoes photolysis to [pyrrole $+\mathrm{CO}$ ]. In matrices, pyrrole and $\mathrm{CO}$ form associates of different geometry, which could be characterized based on their vibrational signatures.
\end{abstract}

\section{Introduction}

Pyrroles are known as common building blocks of many chemical systems of biological interest. Porphyrins (e.g., heme), chlorophylls, and bilanes (e.g., bilirubin) are well-known examples of tetrapyrrole compounds in which the pyrrole rings are interconnected in a cyclic or linear way.

Over the past decades, enormous progress has been achieved in the chemistry of synthetic porphyrins. One possible component to build porphyrins with unsubstituted meso positions, which was originally used by Fischer and Gleim in one of the first syntheses of porphine, ${ }^{1}$ is pyrrole-2-carbaldehyde (P2C). ${ }^{2}$ Understanding of the rotational isomerism in simple prototype molecules, like $\mathrm{P} 2 \mathrm{C}$, can be important in their synthetic applications. $\mathrm{C}=\mathrm{O}$ and $\mathrm{N}-\mathrm{H}$ groups as they occur in $\mathrm{P} 2 \mathrm{C}$, in the $\alpha$ position, are characteristic of amino acid residues in peptides, and the dimer structure of $\mathrm{P} 2 \mathrm{C}$ has been discussed in the context of the peptide $\beta$-sheet motif. ${ }^{3}$ This similarity stimulates further interest to $\mathrm{P} 2 \mathrm{C}$ and its conformational properties.

Previous experiments in the gas phase, by microwave spectroscopy ${ }^{4}$ and infrared in supersonic jet expansion, ${ }^{3}$ and in solutions $\mathrm{s}^{5-7}$ as well as theoretical investigations $\mathrm{s}^{3,5,8}$ showed that $\mathrm{P} 2 \mathrm{C}$ adopts the conformation where the $\mathrm{N}-\mathrm{C}-\mathrm{C}=\mathrm{O}$ dihedral angle is in the cis orientation (Figure 1). The trans conformer has a high relative energy, and its equilibrium population at room temperature was estimated to be very low, «1\%. ${ }^{3}$ Indeed, the experimental observation of the trans conformation of $\mathrm{P} 2 \mathrm{C}$ has not been previously reported. However, in similar molecules, like 3-pyridinecarbaldehyde in the gas phase, ${ }^{9}$ and a series of aromatic aldehydes isolated in cryogenic argon matrices, ${ }^{10,11}$ internal rotation of the aldehyde group has been shown to take place upon UV excitation. For these matrix-isolated molecules, the photoproduced minor conformers could be successfully trapped in the matrix and characterized. ${ }^{10,11}$

* To whom correspondence should be addressed. E-mail: bgiuliano@ qui.uc.pt.

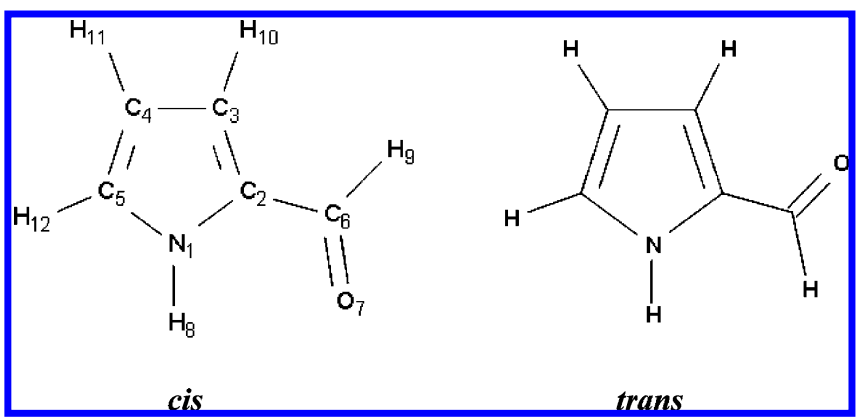

Figure 1. Conformers of pyrrole-2-carbaldehyde (P2C) and adopted atom-numbering scheme.

One of the objectives of the present work was the experimental characterization of the $\mathrm{P} 2 \mathrm{C}$ conformers, with emphasis on its minor form. The method of matrix isolation in solidified inert gases combined with infrared spectroscopy is one of the most appropriate experimental techniques for such studies. Application of this method allowed us to photochemically generate the minor trans conformer of $\mathrm{P} 2 \mathrm{C}$ in cryogenic matrices and undertake its experimental characterization. Theoretical aspects of the conformational structure of P2C are addressed in this work too. In the course of this study, P2C was found to undergo UV-induced photodecomposition. The products of photolysis were characterized by infrared spectroscopy, and the results were interpreted with the aid of methods of theoretical chemistry.

\section{Experimental and Computational Methods}

A commercial sample of P2C (Aldrich, 98\%) was used without further purification.

Matrices were prepared by codeposition of vapors of P2C (kept at room temperature) with a large excess of the matrix gas (argon N60 or xenon N48; both obtained from Air Liquide) onto the CsI optical substrate of the cryostat kept at 10 and 30 $\mathrm{K}$ for Ar and Xe matrices, respectively. An APD Cryogenics 
closed-cycle helium refrigeration system with a DE-202A expander was used in all experiments, the temperature being measured directly at the sample holder by a silicon diode temperature sensor, connected to a digital controller (Scientific Instruments, model 9650-1), with an accuracy of $0.1 \mathrm{~K}$. The matrices were irradiated using a series of long-pass optical filters through a quartz or $\mathrm{KBr}$ external window of the cryostat using a $200 \mathrm{~W}$ output power of a $\mathrm{Hg}(\mathrm{Xe})$ lamp (Oriel, Newport).

The IR spectra were recorded using a Nicolet 6700 Fourier transform infrared spectrometer, equipped with a deuterated triglycine sulfate (DTGS) detector and a Ge/KBr beam splitter, with $0.5 \mathrm{~cm}^{-1}$ spectral resolution. The instrument was purged by a stream of dry air to remove water and $\mathrm{CO}_{2}$ vapors.

The quantum chemical calculations were performed with Gaussian $03^{12}$ at the DFT and MP2 levels of theory using the standard $6-311++\mathrm{G}(\mathrm{d}, \mathrm{p})$ basis set. ${ }^{13}$ In the DFT calculations, the three-parameter density functional B3LYP, which includes Becke's gradient exchange correction ${ }^{14}$ and the Lee, Yang, and Parr correlation functional, ${ }^{15}$ was used. Vibrational spectra were calculated at the same levels of theory, the calculated wavenumbers being later on scaled down using appropriate scale factors in order to correct for vibrational anharmonicity, basis set truncation, and the neglected part of electron correlation. The transition-state structure and energy barrier for conformational interconversion were obtained using the synchronous transit-guided quasi-Newton (STQN) method. ${ }^{16}$ Natural bond orbital (NBO) analysis was performed using NBO 3, as implemented in Gaussian 03, for both cis- and trans-P2C conformers in order to shed light on the dominant orbital interactions in each form.

Normal coordinate analysis was undertaken in the internal coordinates space, as described by Schachtschneider and Mortimer, ${ }^{17}$ using the optimized geometries and harmonic force constants resulting from the DFT calculations. The internal coordinates used in this analysis were defined as recommended by Pulay et al. ${ }^{18}$

\section{Results and Discussion}

Geometries and Relative Energies of Conformers. Figure 1 shows the geometries of the cis and trans conformers of P2C together with the adopted atom-numbering scheme. Both minimum energy structures possess a planar geometry with $C_{s}$ symmetry. The optimized geometrical parameters obtained for the two conformers are given in Table S1 (Supporting Information).

In agreement with the previously reported studies, ${ }^{3-8}$ the DFT calculations yielded the cis conformer considerably more stable than the trans form $\left(\Delta G^{298}\right.$ (trans - cis $\left.)=14.7 \mathrm{~kJ} \mathrm{~mol}^{-1}\right)$, predicting that its abundance in the gas-phase equilibrium conformational mixture at room temperature should be $99.7 \%$. The calculated energy barrier for cis $\rightarrow$ trans conversion was found to be $65.2 \mathrm{~kJ} \mathrm{~mol}^{-1}\left(50.5 \mathrm{~kJ} \mathrm{~mol}^{-1}\right.$ in the reverse direction).

From the energetic point of view, the two conformers of P2C differ essentially in the stabilizing interaction between the bond dipoles associated with the $\mathrm{N}-\mathrm{H}$ and $\mathrm{C}=\mathrm{O}$ bonds. These dipoles are in a nearly antiparallel orientation in the cis conformer and contribute strongly to its stabilization. Such interaction is absent in the trans conformer, where it is replaced by a weaker stabilizing interaction between the $\mathrm{N}-\mathrm{H}$ and aldehyde $\mathrm{C}-\mathrm{H}$ bond dipoles. Note that these interactions are affected by the extension of the electron delocalization within the molecule (Figure 2). Accordingly, it has been proposed that their importance in $\mathrm{P} 2 \mathrm{C}$ is amplified by the extensive electron

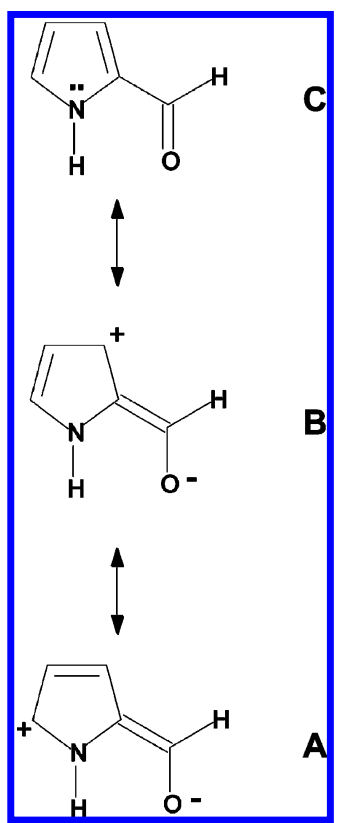

Figure 2. (A and $\mathrm{B}$ ) Mesomeric structures assuming $\pi$-electron delocalization from the nitrogen atom to the carbaldehyde moiety. (C) Dominant canonical form, where such delocalization does not occur.

TABLE 1: Atomic charges (atomic polar tensor, APT, and natural bond orbital, NBO, types) of Cis and Trans Conformers of P2C Obtained from the B3LYP/ 6-311 $++\mathbf{G}(\mathbf{d}, \mathbf{p})$ Calculations

\begin{tabular}{|c|c|c|c|c|}
\hline \multirow{3}{*}{$\begin{array}{c}\text { atom (type } \\
\text { and number) }\end{array}$} & \multicolumn{4}{|c|}{ charges } \\
\hline & \multicolumn{2}{|c|}{ APT } & \multicolumn{2}{|c|}{ NBO } \\
\hline & cis & trans & cis & $\operatorname{trans}$ \\
\hline N1 & -0.254 & -0.198 & -0.503 & -0.509 \\
\hline $\mathrm{C} 2$ & -0.376 & -0.370 & 0.005 & 0.005 \\
\hline $\mathrm{C} 3$ & 0.112 & 0.084 & -0.215 & -0.205 \\
\hline $\mathrm{C} 4$ & -0.191 & -0.201 & -0.294 & -0.284 \\
\hline $\mathrm{C} 5$ & 0.001 & -0.016 & 0.010 & -0.003 \\
\hline C6 & 1.079 & 1.109 & 0.379 & 0.379 \\
\hline $\mathrm{O} 7$ & -0.822 & -0.819 & -0.569 & -0.541 \\
\hline $\mathrm{H} 8$ & 0.261 & 0.243 & 0.423 & 0.406 \\
\hline H9 & -0.046 & -0.080 & 0.118 & 0.096 \\
\hline $\mathrm{H} 10$ & 0.080 & 0.093 & 0.219 & 0.231 \\
\hline H11 & 0.073 & 0.072 & 0.219 & 0.219 \\
\hline H12 & 0.083 & 0.083 & 0.208 & 0.207 \\
\hline
\end{tabular}

delocalization involving the pyrrole ring and the carbaldehyde substituent resulting from the great $\pi$-electron-donating ability of the ring nitrogen atom. ${ }^{3}$

Comparison of geometries of the two conformers supports the proposed interpretation for their relative energies. For example, the $\mathrm{C}=\mathrm{O}$ and $\mathrm{C} 2-\mathrm{C} 3$ bonds are longer and the $\mathrm{C} 2-\mathrm{C} 6$ bond is shorter in the cis than in the trans conformer (122.08, 139.23, and $144.52 \mathrm{pm}$ in cis vs 121.53, 139.04, and $144.90 \mathrm{pm}$ in trans; see Table S1 (Supporting Information)), testifying to the delocalization within the $\pi$ system from the pyrrole ring to the carbonyl group (see Figure 2). Moreover, analysis of the intramolecular Coulombic interactions leads to the same conclusion. The calculated atomic polar tensor (APT) charges $^{19}$ are shown in Table 1. The main dipole-dipole interaction between the ring and the carbaldehyde group occurs between the $\mathrm{N}-\mathrm{H}$ moiety of the ring (for both forms) and $\mathrm{C}=\mathrm{O}$ (cis) or $\mathrm{C}-\mathrm{H}$ (trans) bond dipole of the $\mathrm{CHO}$ group. In both conformers these dipoles are antiparallel and stabilizing, but in the cis form this stabilizing interaction is much stronger than 
TABLE 2: Selected Natural Bond Orbitals of P2C (cis conformer) Obtained from the B3LYP/6-311++G(d,p) Calculations

\begin{tabular}{|c|c|c|c|c|}
\hline \multirow[b]{2}{*}{ bond orbital $^{a} \mathrm{~T}(\mathrm{~A}-\mathrm{B})$} & \multirow[b]{2}{*}{ occupancy $^{b}(e)$} & \multicolumn{2}{|c|}{ coefficients $(\%)^{c}$} & \multirow[b]{2}{*}{ description $^{d}$} \\
\hline & & $A$ & $B$ & \\
\hline$\sigma(\mathrm{N} 1-\mathrm{C} 2)$ & 1.98427 & 62.22 & 37.78 & $0.7888 \mathrm{sp}^{(1.84)}+0.6147 \mathrm{sp}^{(2.80)}$ \\
\hline$\sigma(\mathrm{N} 1-\mathrm{H} 8)$ & 1.98928 & 71.80 & 28.20 & $0.8473 \mathrm{sp}^{(2.47)}+0.5310 \mathrm{~s}$ \\
\hline$\sigma(\mathrm{C} 2-\mathrm{C} 3)$ & 1.97568 & 51.37 & 48.63 & $0.7167 \mathrm{sp}^{(1.66)}+0.6973 \mathrm{sp}^{(1.99)}$ \\
\hline$\pi(\mathrm{C} 2-\mathrm{C} 3)$ & 1.74020 & 53.18 & 46.82 & $0.7292 p+0.6843 p$ \\
\hline$\sigma(\mathrm{C} 2-\mathrm{C} 6)$ & 1.98490 & 52.94 & 47.06 & $0.7276 \mathrm{sp}^{(1.78)}+0.6860 \mathrm{sp}^{(1.68)}$ \\
\hline$\sigma(\mathrm{C} 4-\mathrm{C} 5)$ & 1.97945 & 49.50 & 50.50 & $0.7035 \mathrm{sp}^{(1.99)}+0.7106 \mathrm{sp}^{(1.59)}$ \\
\hline$\pi(\mathrm{C} 4-\mathrm{C} 5)$ & 1.76749 & 52.64 & 47.36 & $0.7255 p+0.6882 p$ \\
\hline$\sigma(\mathrm{C} 4-\mathrm{H} 11)$ & 1.98500 & 61.06 & 38.94 & $0.7814 \mathrm{sp}^{(2.09)}+0.6240 \mathrm{~s}$ \\
\hline$\sigma(\mathrm{C} 5-\mathrm{H} 12)$ & 1.98651 & 60.55 & 39.45 & $0.7781 \mathrm{sp}^{(1.99)}+0.6281 \mathrm{~s}$ \\
\hline$\sigma(\mathrm{C} 6-\mathrm{O} 7)$ & 1.99606 & 35.36 & 64.64 & $0.5947 \mathrm{sp}^{(2.07)} \mathrm{d}^{(0.01)}+0.8040 \mathrm{sp}^{(1.49)}$ \\
\hline$\pi(\mathrm{C} 6-\mathrm{O} 7)$ & 1.97988 & 32.13 & 67.87 & $0.5669 p+0.8238 p$ \\
\hline $\mathrm{Cr}(\mathrm{C} 4)$ & 1.99919 & & & $\mathrm{~s}$ \\
\hline $\mathrm{Cr}(\mathrm{C} 5)$ & 1.99924 & & & s \\
\hline $\mathrm{Cr}(\mathrm{C} 6)$ & 1.99932 & & & $\mathrm{~s}$ \\
\hline $\mathrm{Cr}(\mathrm{O} 7)$ & 1.99978 & & & s \\
\hline LP(N1) & 1.56112 & & & $\mathrm{p}$ \\
\hline LP1(O7) & 1.98572 & & & $\mathrm{sp}^{(0.67)}$ \\
\hline LP2(O7) & 1.88464 & & & $\mathrm{p}$ \\
\hline $\mathrm{Ry} *(\mathrm{C} 6)$ & 0.01123 & & & $\mathrm{sp}^{(3.18)}$ \\
\hline$\sigma^{*}(\mathrm{~N} 1-\mathrm{C} 2)$ & 0.02764 & 37.78 & 62.22 & $0.6147 \mathrm{sp}^{(1.84)}-0.7888 \mathrm{sp}^{(2.80)}$ \\
\hline$\sigma^{*}(\mathrm{~N} 1-\mathrm{C} 5)$ & 0.01310 & 37.12 & 62.88 & $0.6092 \mathrm{sp}^{(1.78)}-0.7930 \mathrm{sp}^{(2.58)}$ \\
\hline$\sigma^{*}(\mathrm{~N} 1-\mathrm{H} 8)$ & 0.01836 & 28.20 & 71.80 & $0.5310 \mathrm{sp}^{(2.47)}-0.8473 \mathrm{~s}$ \\
\hline$\sigma^{*}(\mathrm{C} 2-\mathrm{C} 3)$ & 0.01647 & 48.63 & 51.37 & $0.6973 \mathrm{sp}^{(1.66)}-0.7167 \mathrm{sp}^{(1.99)}$ \\
\hline$\sigma^{*}(\mathrm{C} 2-\mathrm{C} 3)$ & 0.40223 & 46.82 & 53.18 & $0.6843 p-0.7292 p$ \\
\hline$\pi^{*}(\mathrm{C} 6-\mathrm{O} 7)$ & 0.18007 & 67.87 & 32.13 & $0.8238 \mathrm{p}-0.5669 \mathrm{p}$ \\
\hline$\sigma^{*}(\mathrm{C} 6-\mathrm{H} 9)$ & 0.06318 & 42.42 & 57.58 & $0.6513 \mathrm{sp}^{(2.27)}-0.7588 \mathrm{~s}$ \\
\hline
\end{tabular}

${ }^{a}$ See atom numbering in Figure 1. Cr, core orbital; LP, lone electron pair orbital; Ry*, Rydberg orbital. ${ }^{b}$ Occupancy is given with an exaggerated accuracy, as in the Gaussian output file. ${ }^{c}$ The $A$ and $B$ values correspond to the contributions of the atomic orbitals of the two atoms forming a bond (by order of appearance in the corresponding entry in the first column) for the NBO orbitals, extracted from the polarization coefficients given in the description of the NBO orbitals. ${ }^{d}$ The presented description is made in the space of the input atomic orbitals, as given by the B3LYP/6-311++G(d,p) basis set used in the calculations.

in the trans form as it follows from the analysis of the calculated charges (See Table 1).

A more detailed and powerful analysis of the electronic-type interactions within a molecule can be performed using the natural bond orbital (NBO) approach. ${ }^{20}$ It allows for insight into orbital interactions resulting from the second-order perturbation theory analysis of the Fock matrix..$^{20,21}$ According to this method, orbital interaction energies, $E(2)$, between filled and empty NBOs (including non-Lewis extra valence Rydberg orbitals) are obtained from the second-order perturbation approach

$$
E(2)=\Delta E_{i j}-q_{i} \frac{F_{i j}^{2}}{\varepsilon_{j}-\varepsilon_{i}}
$$

where $F_{i j}^{2}$ is the Fock matrix element between $i$ and $j$ NBO orbitals, $\varepsilon_{j}$ and $\varepsilon_{i}$ are the energies of the acceptor and donor NBOs, and $q_{i}$ is the occupancy of the donor orbital.
The NBOs calculated to have a significant occupancy for the cis and trans conformers are listed in Tables 2 and 3 , respectively. The most relevant NBO interactions for both isomers are listed in Table 4 and plotted in Figure 3 for the most stable conformer (the graphical representation of the interacting orbitals in the trans conformer closely resembles that of the cis form and is omitted from the figure for simplicity).

Tables 2 and 3 also show the percentage ratio of the atomic orbitals on each atom forming a bond for the NBO orbitals extracted from the polarization coefficients. ${ }^{20}$ In agreement with the interpretation based on the NBO atomic charges (see Table 1), ${ }^{22,23}$ the obtained percentages show that the polarization of both the $\mathrm{N}-\mathrm{H}$ and carbonyl bonds is larger in the case of the cis than in the trans conformer. For the latter bond, the larger polarization in the cis conformer is due to its $\pi$ component with the $\sigma$ component being nearly equal in the two conformers.

Another conclusion that can be extracted from Tables 2 and 3 is that in both conformers, as expected, both the $\sigma(\mathrm{C}=\mathrm{O})$ and 
TABLE 3: Selected Natural Bond Orbitals of P2C (trans conformer) Obtained from the B3LYP/6-311++G(d,p) Calculations

\begin{tabular}{|c|c|c|c|c|}
\hline \multirow[b]{2}{*}{ bond orbital ${ }^{a} \mathrm{~T}(\mathrm{~A}-\mathrm{B})$} & \multirow[b]{2}{*}{ occupancy $^{b}(\mathrm{e})$} & \multicolumn{2}{|c|}{ coefficients $(\%)^{c}$} & \multirow[b]{2}{*}{ description $^{d}$} \\
\hline & & $A$ & $B$ & \\
\hline$\sigma(\mathrm{N} 1-\mathrm{C} 2)$ & 1.98580 & 62.56 & 37.44 & $0.7909 \mathrm{sp}^{(1.81)}+0.6119 \mathrm{sp}^{(2.84)}$ \\
\hline$\sigma(\mathrm{N} 1-\mathrm{H} 8)$ & 1.98961 & 70.95 & 29.05 & $0.8423 \mathrm{sp}^{(2.53)}+0.5390 \mathrm{~s}$ \\
\hline$\sigma(\mathrm{C} 2-\mathrm{C} 3)$ & 1.97316 & 51.46 & 48.54 & $0.7174 \mathrm{sp}^{(1.64)}+0.6967 \mathrm{sp}^{(2.00)}$ \\
\hline$\pi(\mathrm{C} 2-\mathrm{C} 3)$ & 1.74180 & 54.01 & 45.99 & $0.7349 p+0.6782 p$ \\
\hline$\sigma(\mathrm{C} 2-\mathrm{C} 6)$ & 1.98469 & 52.88 & 47.12 & $0.7272 \mathrm{sp}^{(1.77)}+0.6865 \mathrm{sp}^{(1.64)}$ \\
\hline$\sigma(\mathrm{C} 4-\mathrm{C} 5)$ & 1.97936 & 49.40 & 50.60 & $0.7028 \mathrm{sp}^{(1.99)}+0.7114 \mathrm{sp}^{(1.58)}$ \\
\hline$\pi(\mathrm{C} 4-\mathrm{C} 5)$ & 1.76635 & 51.74 & 48.26 & $0.7193 p+0.6947 p$ \\
\hline$\sigma(\mathrm{C} 4-\mathrm{H} 11)$ & 1.98478 & 61.06 & 38.94 & $0.7814 \mathrm{sp}^{(2.10)}+0.6240 \mathrm{~s}$ \\
\hline$\sigma(\mathrm{C} 5-\mathrm{H} 12)$ & 1.98647 & 60.51 & 39.49 & $0.7779 \mathrm{sp}^{(1.98)}+0.6284 \mathrm{~s}$ \\
\hline$\sigma(\mathrm{C} 6-\mathrm{O} 7)$ & 1.99573 & 35.39 & 64.61 & $0.5949 \mathrm{sp}^{(2.02)} \mathrm{d}^{(0.01)}+0.8038 \mathrm{sp}^{(1.46)}$ \\
\hline$\pi(\mathrm{C} 6-\mathrm{O} 7)$ & 1.97997 & 33.01 & 66.99 & $0.5746 p+0.8185 p$ \\
\hline $\mathrm{Cr}(\mathrm{C} 4)$ & 1.99919 & & & s \\
\hline $\mathrm{Cr}(\mathrm{C} 5)$ & 1.99924 & & & $\mathrm{~s}$ \\
\hline $\mathrm{Cr}(\mathrm{C} 6)$ & 1.99933 & & & $\mathrm{~s}$ \\
\hline $\mathrm{Cr}(\mathrm{O} 7)$ & 1.99977 & & & s \\
\hline $\mathrm{LP}(\mathrm{N} 1)$ & 1.57426 & & & $\mathrm{p}$ \\
\hline LP1(O7) & 1.98548 & & & $\mathrm{sp}^{(0.68)}$ \\
\hline LP2(O7) & 1.87594 & & & $\mathrm{p}$ \\
\hline $\mathrm{Ry} *(\mathrm{C} 6)$ & 0.01172 & & & $\mathrm{sp}^{(5.41)} \mathrm{d}^{(0.11)}$ \\
\hline$\sigma^{*}(\mathrm{~N} 1-\mathrm{C} 2)$ & 0.02500 & 37.44 & 62.56 & $0.6119 \mathrm{sp}^{(1.81)}-0.7909 \mathrm{sp}^{(2.84)}$ \\
\hline$\sigma^{*}(\mathrm{~N} 1-\mathrm{C} 5)$ & 0.01292 & 36.94 & 63.06 & $0.6078 \mathrm{sp}^{(1.78)}-0.7941 \mathrm{sp}^{(2.60)}$ \\
\hline$\sigma^{*}(\mathrm{~N} 1-\mathrm{H} 8)$ & 0.01828 & 29.05 & 70.95 & $0.5390 \mathrm{sp}^{(2.53)}-0.8423 \mathrm{~s}$ \\
\hline$\sigma^{*}(\mathrm{C} 2-\mathrm{C} 3)$ & 0.01943 & 48.54 & 51.46 & $0.6967 \mathrm{sp}^{(1.64)}-0.7174 \mathrm{sp}^{(2.00)}$ \\
\hline$\sigma^{*}(\mathrm{C} 2-\mathrm{C} 3)$ & 0.39118 & 45.99 & 54.01 & $0.6782 \mathrm{p}-0.7349 \mathrm{p}$ \\
\hline$\pi^{*}(\mathrm{C} 6-\mathrm{O} 7)$ & 0.17244 & 66.99 & 33.01 & $0.8185 p-0.5746 p$ \\
\hline$\sigma^{*}(\mathrm{C} 6-\mathrm{H} 9)$ & 0.07086 & 43.33 & 56.67 & $0.6583 \mathrm{sp}^{(2.38)}-0.7528 \mathrm{~s}$ \\
\hline
\end{tabular}

${ }^{a}$ See atom numbering in Figure 1. Cr, core orbital; LP, lone electron pair orbital; Ry*, Rydberg orbital. ${ }^{b}$ Occupancy is given with an exaggerated accuracy, as in the Gaussian output file. ${ }^{c}$ The $A$ and $B$ values correspond to the contributions of the atomic orbitals of the two atoms forming a bond (by order of appearance in the corresponding entry in the first column) for the NBO orbitals, extracted from the polarization coefficients given in the description of the NBO orbitals. ${ }^{d}$ The presented description is made in the space of the input atomic orbitals, as given by the $6-311++\mathrm{G}(\mathrm{d}, \mathrm{p})$ basis set used in the calculations.

TABLE 4: Stabilization Energies for Selected NBO Pairs As Given by Second Order Perturbation Theory Analysis of the Fock Matrix in the NBO Basis for P2C (conformers cis and trans) Obtained from the B3LYP/6-311++G(d,p) Calculations $^{a}$

\begin{tabular}{cllrr}
\hline & & & \multicolumn{2}{c}{$E(2)^{b}$} \\
\cline { 4 - 5 } pair name & donor NBO & acceptor NBO & \multicolumn{1}{c}{ cis } & \multicolumn{1}{c}{ trans } \\
\hline A & $\pi(\mathrm{C} 2-\mathrm{C} 3)$ & $\pi^{*}(\mathrm{C} 4-\mathrm{C} 5)$ & 77.91 & 81.59 \\
B & $\pi(\mathrm{C} 4-\mathrm{C} 5)$ & $\pi^{*}(\mathrm{C} 2-\mathrm{C} 3)$ & 89.70 & 90.54 \\
$\mathrm{C}$ & LP(N1) & $\pi^{*}(\mathrm{C} 2-\mathrm{C} 3)$ & 149.16 & 136.40 \\
$\mathrm{D}$ & LP(N1) & $\pi^{*}(\mathrm{C} 4-\mathrm{C} 5)$ & 170.37 & 162.21 \\
E & $\pi(\mathrm{C} 2-\mathrm{C} 3)$ & $\pi^{*}(\mathrm{C} 6-\mathrm{O} 7)$ & 104.06 & 96.99 \\
F & LP2(O7) & $\sigma^{*}(\mathrm{C} 2-\mathrm{C} 6)$ & 68.91 & 70.96 \\
G & LP2(O7) & $\sigma^{*}(\mathrm{C} 6-\mathrm{H} 9)$ & 91.88 & 98.32
\end{tabular}

${ }^{a}$ See atom numbering in Figure 1. See Figure 3 where orbitals $\mathrm{A}-\mathrm{G}$ for the cis conformer are shown graphically. LP, lone electron pair orbital. ${ }^{b}$ Energies in $\mathrm{kJ} \mathrm{mol}^{-1}$.

$\pi(\mathrm{C}=\mathrm{O})$ bonding orbitals are strongly polarized, this polarization being opposite regarding the corresponding antibonding orbitals.
Interestingly, the occupancy of the $\pi^{*}(\mathrm{C}=\mathrm{O})$ orbital is larger in the cis $(0.180 e)$ than in the trans $(0.172 e)$ form, clearly revealing the most important $\pi$-electron charge delocalization from the pyrrole ring toward the carbonyl bond. This point will be considered in more detail below.

The descriptions of the NBOs associated with the carbonyl group show that in both conformers the carbonyl carbon atom, as expected, is $\mathrm{sp}^{2}$ hybridized, with the hybrid orbital forming the $\sigma$ bond with $\mathrm{C} 2$ having a larger s character compared to those forming both the $\sigma$ bond with the carbonyl oxygen and the $\mathrm{C}-\mathrm{H}$ bond. Moreover, in the two conformers, the carbonyl oxygen atom is sp hybridized, with one of the two hybrid orbitals forming the $\sigma(\mathrm{C}=\mathrm{O})$ bond and the other being occupied by a lone pair of electrons while the two $\mathrm{p}$ orbitals form the $\pi(\mathrm{C}=\mathrm{O})$ bond and accommodate the second lone electron pair. The occupancy of the sp-hybrid lone-pair orbital of the carbonyl oxygen is relatively high (1.986 and $1.985 e$ in the cis and trans forms, respectively), while that of the second lone-pair orbital 


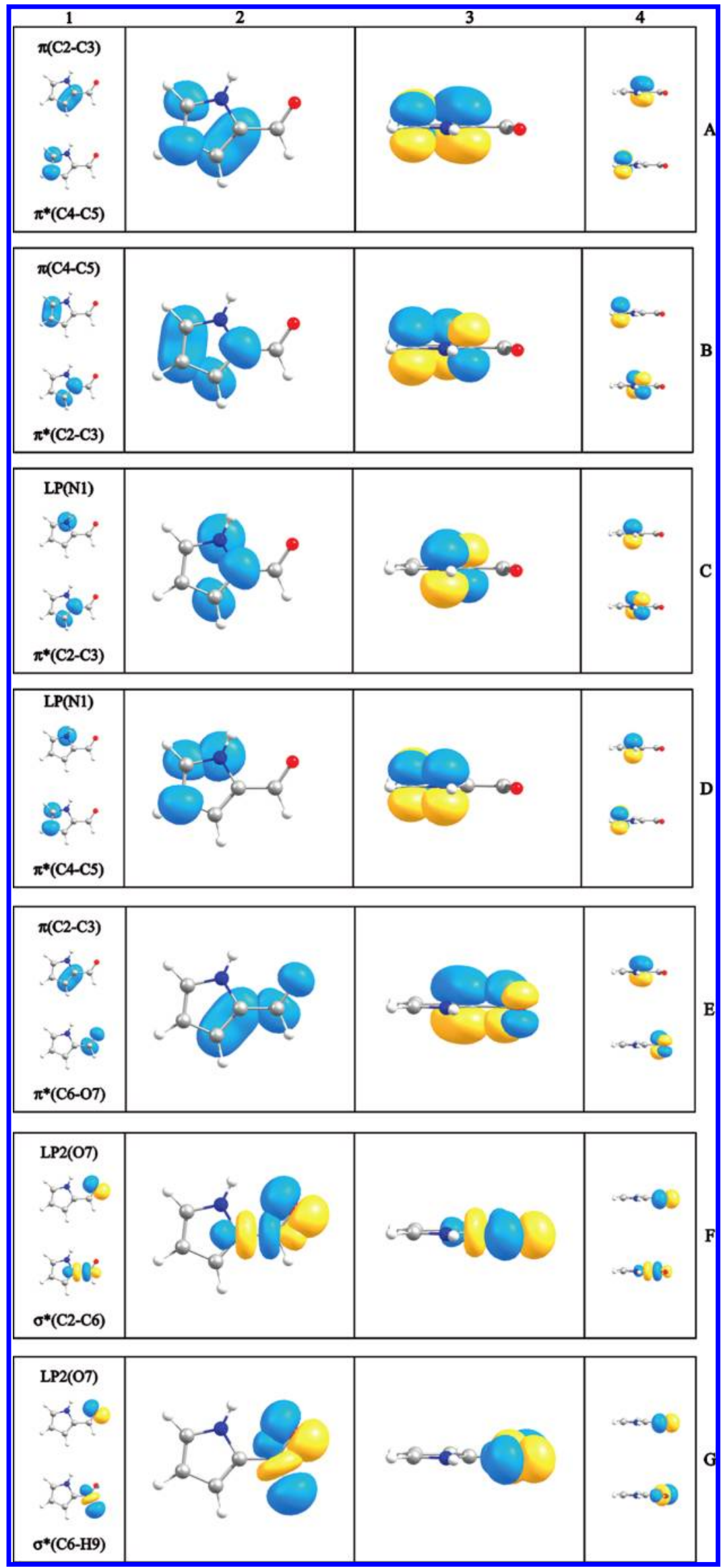

Figure 3. Electron density surfaces of selected NBOs for cis-P2C calculated at the B3LYP/6-311++G(d,p) level of theory showing the dominant orbital interactions (see text for discussion and also Table 4). Yellow and blue colors correspond to negative and positive wave function signs, respectively. Column 1 displays the front views of the donor (upper part) and acceptor (lower part) NBOs. Column 2 displays the front views of superimposed NBOs. Columns 3 and 4 display the side views of superimposed and individual NBOs, respectively. For $\pi$ orbitals, in columns 1 and 2 only the portion of positive sign is shown for clarity. Color codes for atoms: red, oxygen; blue, nitrogen; gray, carbon; white, hydrogen. 
is comparatively low and considerably larger in the cis than in the trans conformer ( $1.884 \mathrm{vs} 1.875 e$ ), indicating that the latter orbital is involved in charge back-donation and that this effect is more important in trans than cis. As discussed below, this back-donation occurs in the direction of both the $\mathrm{C} 2-\mathrm{C} 6$ bond and, predominantly, $\mathrm{C}-\mathrm{H}$ aldehyde bond. The relative importance of the oxygen lone electron pair p orbital for the $\sigma^{*}(\mathrm{C}-\mathrm{H})$ orbital back-donation is also revealed by its relative occupancies in the two conformers $(0.063 e$ in cis vs $0.070 e$ in trans; see Tables 2 and 3).

As shown in Table 4, the most important NBO interactions in both $\mathrm{P} 2 \mathrm{C}$ conformers are of the same type. However, their relative importance is significantly different. The interactions associated with the $\pi$ system are clearly more important for the cis than for the trans form, whereas the opposite trend is found for NBO interactions associated with the $\sigma$ system.

The greater importance of the $\pi$-type interactions in cis is in agreement with the more relevant $\pi$-electron delocalization in this form already pointed out above and extracted from the structural data, atomic charges, and NBO descriptions and polarizations. Orbital interactions of types A and B in Table 4 reflect the delocalization over the carbon atoms of the pyrrole ring, those of types $\mathrm{C}$ and $\mathrm{D}$ between the nitrogen lone electron pair and the carbon ring atoms, and, finally, that of type $\mathrm{E}$ between the $\mathrm{C} 2-\mathrm{C} 3$ bond of the pyrrole ring and the carbonyl group (see also Figure 3). On the whole, these interactions show the larger importance of the mesomeric structures A and B (see Figure 2) in cis- than in trans-P2C. As extracted from Table 4 (lines $\mathrm{A}-\mathrm{E}$, inclusive), the $\pi$-system stabilizing energy in the cis form is larger than in the trans form by $23.47 \mathrm{~kJ} \mathrm{~mol}^{-1}$.

On the other hand, the $\sigma$-type NBO interactions ( $\mathrm{F}$ and $\mathrm{G}$ in Table 4) are slightly greater in trans- than in cis-P2C. This shows that the back-donation from the oxygen lone electron pairs (specifically the p-type lone pair; LP2) to the C2-C6 bond and, in particular, to the $\mathrm{C}-\mathrm{H}$ aldehyde bond is more important in trans- than in cis-P2C. This back-donation effect is well known and was described long ago as the most important effect leading to the observed elongation of a $\mathrm{C}-\mathrm{H}$ bond connected to a carbonyl moiety as well as to its reduced $\mathrm{C}-\mathrm{H}$ stretching frequency (e.g., in aldehydes and formic acid derivatives). ${ }^{24-26}$ The reasons for the slightly greater importance of this effect in trans-P2C compared to cis-P2C were not fully understood, but one possibility is that it is, at least partially, a consequence of the closest proximity between the oxygen and the aldehyde hydrogen atoms in the trans conformer, where the $\mathrm{O}=\mathrm{CH}$ angle is smaller than in the cis form $\left(120.27^{\circ}\right.$ vs $\left.121.17^{\circ}\right)$. The difference in the value of this angle in the two conformers is, however, small enough to lead us to present such a hypothesis just as a tentative one.

Interestingly, the energy difference in the seven main stabilizing NBO interactions in cis- and trans-P2C shown in Table 4 amounts to $14.98 \mathrm{~kJ} \mathrm{~mol}^{-1}$, i.e., it matches very well the calculated electronic energy difference (at the B3LYP level of theory) between the two conformers $\left(\Delta E=16.1 \mathrm{~kJ} \mathrm{~mol}^{-1}\right)$, providing strong evidence of the prevalence of strictly electronic factors for the relative stability of the two conformers.

Assignment of Infrared Spectra and Photoinduced Conformational Isomerization. Figure 4 shows the infrared spectra (1800-500 $\mathrm{cm}^{-1}$ frequency range) of P2C isolated in argon and xenon matrices (spectra A and B, respectively) as well as a simulated spectrum for the cis conformer (spectrum C). In agreement with previous experiments in the gas and liquid phases $^{3-7}$ and theoretical predictions, the spectra of P2C isolated in argon and xenon matrices only show bands attributable to

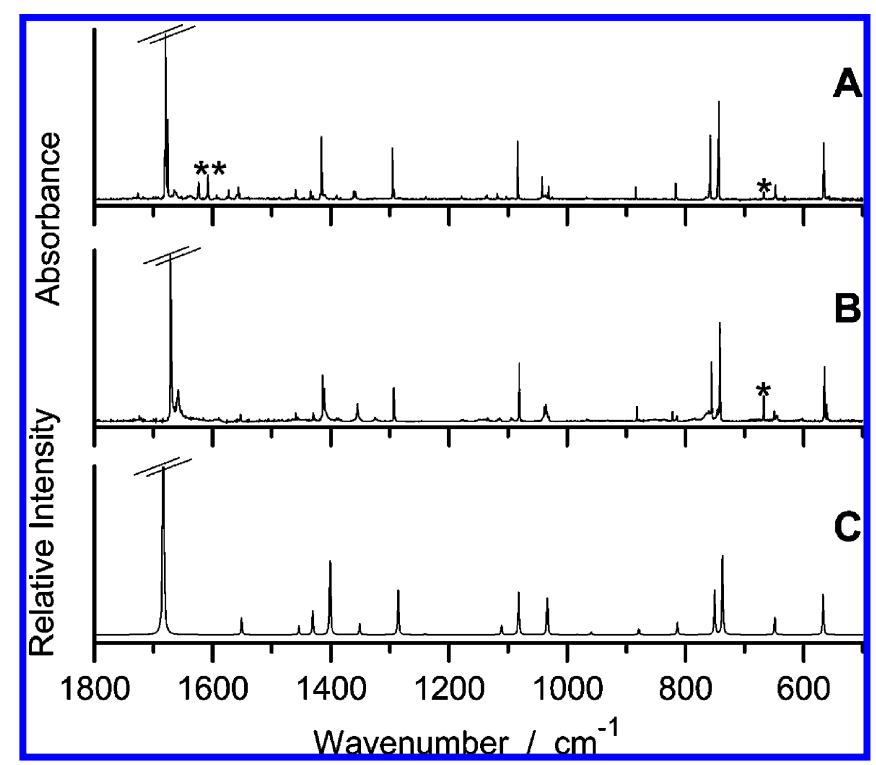

Figure 4. Spectra of $\mathrm{P} 2 \mathrm{C}$ isolated in freshly deposited $\mathrm{Ar}$ and $\mathrm{Xe}$ matrices (frames A and B, respectively), compared with a simulated infrared spectrum of monomeric cis-P2C (frame C). The simulated spectrum was obtained using Lorentzian functions centered at the scaled calculated wavenumbers using bandwidths at half-height (fwhm) equal to $2 \mathrm{~cm}^{-1}$. The scaling factor for the calculated B3LYP/6-311++G(d,p) frequencies was equal to 0.978 . The bands marked with an asterisk (*) are associated with matrix-isolated traces of monomeric water or $\mathrm{CO}_{2}$. Bands due to the $\mathrm{C}=\mathrm{O}$ stretching vibration are truncated.

the cis conformer. Table 5 summarizes the assignments (note FR for $v \mathrm{CH}$, ref 24) of the observed infrared spectra of the cis conformer and presents the corresponding calculated data and results of normal coordinates analysis. The definitions of the internal coordinates used in this analysis are given in Table S2 (Supporting Information). The good reproduction of the experimental spectra by the calculations made the assignment straightforward. For most of the bands, extensive site splitting occurs in both argon and xenon matrices. This is particularly evident for the most intense bands, corresponding to vibrations localized predominantly on more polarizable molecular fragments, which could be expected a priori to be more strongly affected by the matrix media.

UV irradiation $(\lambda>235 \mathrm{~nm})$ of the matrices was found to lead to noticeable spectral changes. Use of different cutoff filters, as described in the Experimental Section, allowed us to conclude that irradiation at $\lambda>320 \mathrm{~nm}$ is not effective in promoting any photoreactions, since the spectra obtained under those conditions have not shown any changes in relation to the spectra of nonirradiated matrices.

Figure 5 summarizes the changes in spectra resulting from UV irradiation $(\lambda>235 \mathrm{~nm})$. The downward bands in the difference spectra are associated with the cis conformer whose population decreased upon irradiation, while the upward bands are related with new species appearing upon irradiation. The latter fit nicely with the calculated spectrum of the trans conformer of $\mathrm{P} 2 \mathrm{C}$, testifying to the $\mathrm{UV}$-induced conversion of the most stable cis conformer into the trans form. Figure 5 presents also the calculated difference spectra (trans minus cis) for comparison with the experimental data. The good agreement between the experimental and calculated spectra allowed for the straightforward assignment of the new bands in the spectra of irradiated matrices to the trans species of P2C. These assignments are summarized in Table 6.

Like pointed out above for the cis conformer, several bands of the newly formed trans conformer also appear split into 
TABLE 5: Observed Wavenumbers (v) and IR Intensities (I, qualitative) for the Cis Form of Pyrrole-2-carbaldehyde Monomer in Argon and Xenon Matrices and Band Assignments ${ }^{a}$

\begin{tabular}{|c|c|c|c|c|c|c|c|}
\hline \multicolumn{2}{|c|}{ calculated } & \multicolumn{2}{|l|}{$\operatorname{Ar}(10 \mathrm{~K})$} & \multicolumn{2}{|l|}{$\mathrm{Xe}(30 \mathrm{~K})$} & \multirow[b]{2}{*}{ sym. } & \multirow[b]{2}{*}{$\operatorname{PED}^{b}(\%)$} \\
\hline$v$ & $I$ & $v$ & $I$ & $v$ & $I$ & & \\
\hline 3560.0 & 100.8 & $3477.5, \mathbf{3 4 7 5 . 7}$ & $\mathrm{S}$ & $3466.6, \mathbf{3 4 6 3 . 4}, 3457.8$ & $\mathrm{~S}$ & $\mathrm{~A}^{\prime}$ & $v(\mathrm{~N} 1-\mathrm{H} 8)(100)$ \\
\hline 3188.6 & 0.5 & n.o. & & n.o. & & $\mathrm{A}^{\prime}$ & $v(\mathrm{C}-\mathrm{H}) \mathrm{R} 1(97)$ \\
\hline 3174.1 & 1.3 & n.o. & & n.o. & & $\mathrm{A}^{\prime}$ & $v(\mathrm{C}-\mathrm{H}) \mathrm{R} 2(101)$ \\
\hline 3163.1 & 1.5 & n.o. & & n.o. & & $\mathrm{A}^{\prime}$ & $v(\mathrm{C}-\mathrm{H}) \mathrm{R} 3(97)$ \\
\hline 2865.2 & 101.0 & $\begin{array}{l}2854.6,2850.6,2848.9 \\
2846.8, \mathbf{2 8 4 2 . 7}, 2839.4 \\
2812.1\end{array}$ & S & $\begin{array}{l}\mathbf{2 8 2 2 . 9}, 2820.2,2813.7 \\
2800.3,2797.1, \mathbf{2 7 9 2 . 2}\end{array}$ & $\mathrm{S}$ & $\mathrm{A}^{\prime}$ & $v(\mathrm{C} 6-\mathrm{H} 9)(100)+\mathrm{FR}$ with $2 * \delta(\mathrm{C} 2 \mathrm{C} 6 \mathrm{H} 9)$ \\
\hline 1683.3 & 469.2 & $1681.1, \mathbf{1 6 7 9 . 6}, 1676.1$ & $\mathrm{vS}$ & 1671.0 & $\mathrm{vS}$ & $\mathrm{A}^{\prime}$ & $v(\mathrm{C} 6-\mathrm{O} 7)(84)$ \\
\hline 1550.5 & 20.6 & $1559.2, \mathbf{1 5 5 6 . 7}, 1554.1$ & w & $\mathbf{1 5 5 3 . 0}, 1551.9$ & $\mathrm{~W}$ & $\mathrm{~A}^{\prime}$ & $\begin{array}{l}v(\mathrm{C} 2=\mathrm{C} 3)(30)+\delta(\mathrm{C} 5-\mathrm{H} 12)(22)+v(\mathrm{C} 4=\mathrm{C} 5)(15)+\delta(\mathrm{NH})(11)+ \\
v(\mathrm{C} 2-\mathrm{C} 6)(11)\end{array}$ \\
\hline 1454.0 & 10.9 & 1459.6, 1456.6 & w & 1459.4, 1455.7 & w & $\mathrm{A}^{\prime}$ & $\begin{array}{l}v(\mathrm{C} 5-\mathrm{N} 1)(19)+\delta(\mathrm{C} 5-\mathrm{H} 12)(15)+\delta(\mathrm{NH})(11)+v(\mathrm{C} 4=\mathrm{C} 5)(10)+ \\
\delta(\mathrm{C} 2 \mathrm{C} 6 \mathrm{H} 9)(10)\end{array}$ \\
\hline 1430.5 & 29.6 & 1433.9, 1430.1 & w & 1429.6, 1427.0 & $\mathrm{~W}$ & $\mathrm{~A}^{\prime}$ & $v(\mathrm{C} 5-\mathrm{N} 1)(20)+v(\mathrm{C} 2=\mathrm{C} 3)(12)+\delta(\mathrm{C} 3-\mathrm{H} 10)(10)$ \\
\hline 1401.3 & 93.7 & 1416.0 & $\mathrm{~S}$ & 1414.2, 1411.2 & $\mathrm{~S}$ & $A^{\prime}$ & $v(\mathrm{C} 4=\mathrm{C} 5)(22)+v(\mathrm{~N} 1-\mathrm{C} 2)(22)+\delta(\mathrm{C} 4-\mathrm{H} 11)(20)+\delta(\mathrm{R} 1)(13)$ \\
\hline 1350.9 & 13.8 & $1361.2,1358.6$ & w & 1354.9 & w & $A^{\prime}$ & $\delta(\mathrm{C} 2 \mathrm{C} 6 \mathrm{H} 9)(56)+\delta(\mathrm{C} 2 \mathrm{C} 6 \mathrm{O} 7)(10)$ \\
\hline 1286.0 & 54.8 & $\mathbf{1 2 9 5 . 5}, 1293.4,1292.7$ & $\mathrm{~m}$ & 1293.4, 1292.5 & $\mathrm{~m}$ & $A^{\prime}$ & $\begin{array}{l}v(\mathrm{C} 3-\mathrm{C} 4)(27)+v(\mathrm{C} 2-\mathrm{C} 6)(19)+\delta(\mathrm{C} 5-\mathrm{H} 12)(13)+v(\mathrm{C} 5-\mathrm{N} 1)(10)+ \\
v(\mathrm{~N} 1-\mathrm{C} 2)(10)\end{array}$ \\
\hline 1240.6 & 1.3 & 1239.2 & w & n.o. & & $\mathrm{A}^{\prime}$ & $\delta(\mathrm{C} 4-\mathrm{H} 11)(31)+\delta(\mathrm{NH})(21)+v(\mathrm{C} 3-\mathrm{C} 4)(10)$ \\
\hline 1111.2 & 11.9 & 1118.7 & $\mathrm{~W}$ & n.o. & & $A^{\prime}$ & $\delta(\mathrm{C} 4-\mathrm{H} 11)(36)+\delta(\mathrm{NH})(17)+v(\mathrm{C} 4=\mathrm{C} 5)(16)+v(\mathrm{C} 5-\mathrm{N} 1)$ \\
\hline 1082.3 & 52.9 & 1084.0 & $\mathrm{~m}$ & 1081.2 & $\mathrm{~m}$ & $A^{\prime}$ & $v(\mathrm{C} 4=\mathrm{C} 5)(26)+\delta(\mathrm{NH})(26)+v(\mathrm{C} 5-\mathrm{N} 1)(25)+\delta(\mathrm{C} 5-\mathrm{H} 12)(12)$ \\
\hline 1033.9 & 46.0 & 1042.7, 1031.6 & $\mathrm{~m}$ & $1038.4, \mathbf{1 0 3 5 . 9}, 1031.0$ & $\mathrm{~m}$ & $\mathrm{~A}^{\prime}$ & $\delta(\mathrm{C} 3-\mathrm{H} 10)(66)+v(\mathrm{C} 3-\mathrm{C} 4)(34)$ \\
\hline 983.0 & 0.2 & n.o. & & n.o. & & $\mathrm{A}^{\prime \prime}$ & $\gamma(\mathrm{H} 9-\mathrm{C} 6)(96)$ \\
\hline 959.8 & 3.4 & 967.4 & $\mathrm{~W}$ & n.o. & & $\mathrm{A}^{\prime}$ & $\delta(\mathrm{R} 1)(31)+v(\mathrm{~N} 1-\mathrm{C} 2)(26)+\delta(\mathrm{C} 5-\mathrm{H} 12)(15)+v(\mathrm{C} 2=\mathrm{C} 3)$ \\
\hline 881.0 & 0.4 & n.o. & & n.o. & & $\mathrm{A}^{\prime \prime}$ & $\gamma(\mathrm{CH}) \mathrm{R} 1(117)$ \\
\hline 878.8 & 7.2 & 884.2 & W & 882.1 & W & $\mathrm{A}^{\prime}$ & $\delta(\mathrm{R} 2)(88)$ \\
\hline 813.7 & 14.8 & 816.6 & $\mathrm{~W}$ & 821.9, 814.6 & $\mathrm{~W}$ & $\mathrm{~A}^{\prime \prime}$ & $\gamma(\mathrm{CH}) \mathrm{R} 2(102)$ \\
\hline 750.6 & 54.0 & $759.6, \mathbf{7 5 8 . 3}$ & $\mathrm{m}$ & 755.8 & $\mathrm{~m}$ & $\mathrm{~A}^{\prime}$ & $\delta(\mathrm{C} 2 \mathrm{C} 6 \mathrm{O} 7)(35)+\delta(\mathrm{R} 1)$ \\
\hline 737.5 & 96.6 & $745.7,743.9$ & $S$ & $745.9, \mathbf{7 4 2 . 0}$ & $S$ & $\mathrm{~A}^{\prime \prime}$ & $\gamma(\mathrm{CH}) \mathrm{R} 3(95)$ \\
\hline 649.0 & 20.6 & 647.5 & $\mathrm{~W}$ & 667.6 & $\mathrm{w}$ & $\mathrm{A}^{\prime \prime}$ & $\tau(\mathrm{R} 2)(64)+\tau(\mathrm{R} 1)(21)+\gamma(\mathrm{N} 1-\mathrm{H} 8)$ \\
\hline 614.9 & 0.0003 & n.o. & & n.o. & & $\mathrm{A}^{\prime \prime}$ & $\tau(\mathrm{R} 1)(56)+\tau(\mathrm{R} 2)(32)+\gamma(\mathrm{N} 1-\mathrm{H} 8)(13)$ \\
\hline 567.2 & 48.7 & $567.2, \mathbf{5 6 5 . 7}, 564.8$ & $\mathrm{~m}$ & 564.9, 561.1 & $\mathrm{~m}$ & $\mathrm{~A}^{\prime \prime}$ & $\gamma(\mathrm{N} 1-\mathrm{H} 8)(68)+\tau(\mathrm{R} 1)(32)$ \\
\hline 494.3 & 0.6 & n.o. & & n.o. & & $\mathrm{A}^{\prime}$ & $\begin{array}{l}v(\mathrm{C} 2-\mathrm{C} 6)(30)+\delta(\mathrm{C} 2 \mathrm{C} 6 \mathrm{O} 7)(24)+\delta(\mathrm{R} 1)(19)+v(\mathrm{C} 2=\mathrm{C} 3) \\
{[\delta(\mathrm{C} 6 \mathrm{C} 2 \mathrm{C} 3)+\delta(\mathrm{C} 6 \mathrm{C} 2 \mathrm{~N} 1)](11)}\end{array}$ \\
\hline 293.2 & 19.4 & n.i. & & n.i. & & $\mathrm{A}^{\prime \prime}$ & $\tau(\mathrm{C} 6-\mathrm{C} 2)(50)+\gamma(\mathrm{C} 6-\mathrm{C} 2)(34)+\tau(\mathrm{R} 2)(13)$ \\
\hline 192.0 & 13.8 & n.i. & & n.i. & & $\mathrm{A}^{\prime}$ & {$[\delta(\mathrm{C} 6 \mathrm{C} 2 \mathrm{C} 3)+\delta(\mathrm{C} 6 \mathrm{C} 2 \mathrm{~N} 1)](70)+\delta(\mathrm{C} 2 \mathrm{C} 6 \mathrm{O} 7)(25)$} \\
\hline 145.6 & 2.8 & n.i. & & n.i. & & $\mathrm{A}^{\prime \prime}$ & $\tau(\mathrm{C} 6-\mathrm{C} 2)(49)+\gamma(\mathrm{C} 6-\mathrm{C} 2)(47)$ \\
\hline
\end{tabular}

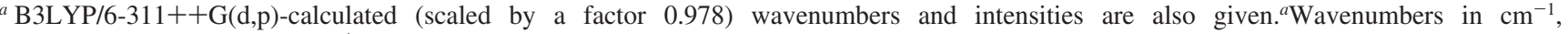
calculated intensities in $\mathrm{km} \mathrm{mol}^{-1} . \nu$, bond stretching; $\delta$, bending; $\gamma$, rocking; $\tau$, torsion; w, wagging; tw, twisting; FR, Fermi resonance; s, symmetric; as, antisymmetric; n.o., not observed; n.i., not investigated; w, weak; m, medium; S, strong; vS, very strong. ${ }^{b}$ PEDs lower than $10 \%$ are not included. Definition of symmetry coordinates is given in Table S1 (Supporting Information). See Figure 1 for atom numbering.

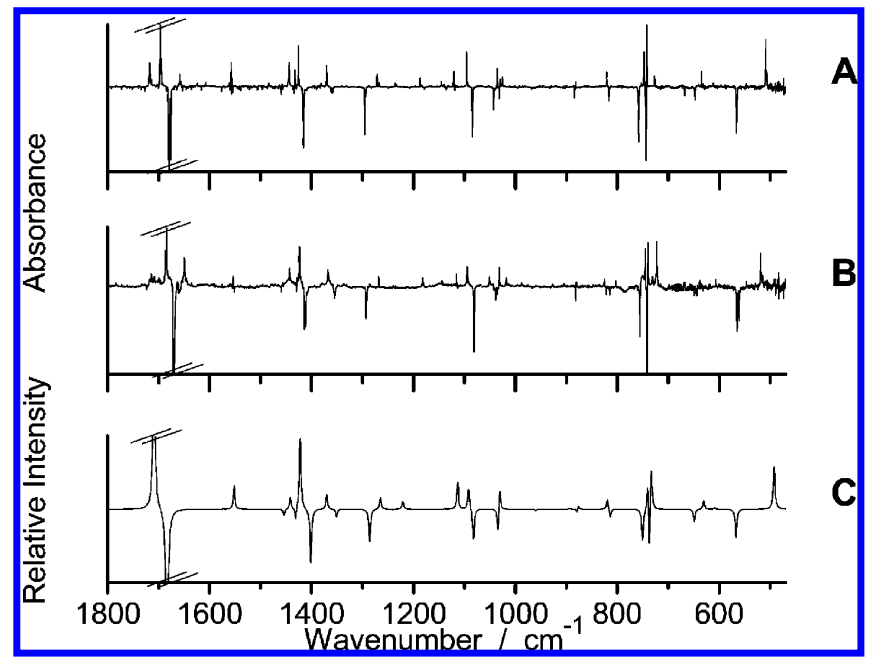

Figure 5. Changes in the experimental spectra of $\mathrm{P} 2 \mathrm{C}$ isolated in argon (A) and xenon matrices (B) after 20 min of UV irradiation $(\lambda>235$ $\mathrm{nm})$. Negative absorptions correspond to decreasing bands of the initially present cis form. Positive peaks correspond to new absorptions due to the photoproduct(s). Simulated theoretical spectrum obtained as "trans minus cis" (C). Absorptions due to the individual conformers were simulated with Lorentzian functions ( $\mathrm{fwhm}=2 \mathrm{~cm}^{-1}$ ) centered at the calculated DFT(B3LYP)/6-311++G(d,p) frequencies. Bands in the $\mathrm{C}=\mathrm{O}$ stretching region are truncated.

several components due to matrix site effects. Interestingly, bands belonging to different sites were found to show the same behavior upon irradiation, implying that local matrix-solute interactions do not influence significantly the photoinduced conformational isomerization.

The appearance of the new bands due to the trans conformer was found to be very fast, the bands being detectable already after the first minute of irradiation. Spectra recorded at different stages of irradiation showed that growth of the new bands slowed down. After prolonged irradiation, bands due to the trans conformer started to decrease along with the cis bands, indicating the occurrence of an additional photochemical reaction, which will be addressed later. Notably, in the progress of irradiation, the population ratio of the two $\mathrm{P} 2 \mathrm{C}$ conformers practically stopped changing. This behavior is compatible with the attainment of a photostationary state. Interestingly, there seems to be no heavy-atom effect on the position of the photostationary state, which establishes at a level of [cis]/[trans] $\approx 3.3$ for both matrix media (see Figure 6).

As shown in Figure 6, the profile of the kinetical curves with time of irradiation is slightly different for the photochemistry in argon and xenon matrices. In argon, the photostationary state for conformational isomerization was attained after ca. $1 \mathrm{~h}$ of irradiation, whereas in xenon it was about twice faster. The explanation of the different behavior observed in argon and xenon matrices might be related to the presence of additional photochemical channels in argon. Indeed, it is possible that in argon P2C undergoes valence isomerization to its Dewar form, as indicated by the appearance in the spectra of irradiated samples of a weak absorption at $1717 \mathrm{~cm}^{-1}$ (ca. $40 \mathrm{~cm}^{-1}$ higher than for cis-P2C) that might be ascribed to the Dewar isomer. 
TABLE 6: Observed Wavenumbers ( $v$ ) and IR Intensities ( $I$, qualitative) for the Trans Form of Pyrrole-2-carbaldehyde Monomer in Argon and Xenon Matrices and Band Assignments ${ }^{a}$

\begin{tabular}{|c|c|c|c|c|c|c|c|}
\hline \multicolumn{2}{|c|}{ calculated } & \multicolumn{2}{|l|}{$\operatorname{Ar}(10 \mathrm{~K})$} & \multicolumn{2}{|l|}{$\mathrm{Xe}(30 \mathrm{~K})$} & \multirow[b]{2}{*}{ sym } & \multirow[b]{2}{*}{$\operatorname{PED}^{b}(\%)$} \\
\hline$v$ & $I$ & $v$ & $I$ & $v$ & $I$ & & \\
\hline 3568.7 & 75.0 & $\mathbf{3 4 8 7 . 4}, 3484.5$ & $\mathrm{~m}$ & $\mathbf{3 4 6 9 . 5}, 3468.0$ & $\mathrm{~m}$ & $\mathrm{~A}^{\prime}$ & $v(\mathrm{~N} 1-\mathrm{H} 8)(100)$ \\
\hline 3182.4 & 0.02 & n.o. & & n.o. & & $\mathrm{A}^{\prime}$ & $v(\mathrm{C}-\mathrm{H}) \mathrm{R} 2(90)$ \\
\hline 3167.3 & 1.8 & n.o. & & n.o. & & $\mathrm{A}^{\prime}$ & $v(\mathrm{C}-\mathrm{H}) \mathrm{R} 3(92)$ \\
\hline 2781.3 & 153.2 & $2766.8,2756.3$ & $\mathrm{~S}$ & 2750.9 & $\mathrm{~S}$ & $\mathrm{~A}^{\prime}$ & $v(\mathrm{C} 6-\mathrm{H} 9)(100)$ \\
\hline 1709.1 & 419.8 & $1698.2, \mathbf{1 6 9 6 . 6}, 1695.1$ & $\mathrm{vS}$ & $1686.6, \mathbf{1 6 8 4 . 3}$ & $\mathrm{vS}$ & $\mathrm{A}^{\prime}$ & $v(\mathrm{C} 6-\mathrm{O} 7)(86)$ \\
\hline 1429.3 & 10.4 & 1432.8 & $\mathrm{w}$ & n.o & & $\mathrm{A}^{\prime}$ & $\begin{array}{l}\delta(\mathrm{C} 2 \mathrm{C} 6 \mathrm{H} 9)(24)+v(\mathrm{~N} 1-\mathrm{C} 2)(22)+\delta(\mathrm{NH})(18)+v(\mathrm{C} 2=\mathrm{C} 3) \\
(16)\end{array}$ \\
\hline 1422.1 & 123.2 & 1425.6 & $\mathrm{~S}$ & 1423.9 & S & $\mathrm{A}^{\prime}$ & $\begin{array}{l}v(\mathrm{C} 4=\mathrm{C} 5)(23)+\delta(\mathrm{C} 2 \mathrm{C} 6 \mathrm{H} 9)(14)+v(\mathrm{C} 2-\mathrm{C} 6)(13)+\delta(\mathrm{R} 1)(10) \\
+v(\mathrm{C} 2=\mathrm{C} 3)(10)+\delta(\mathrm{C} 5-\mathrm{H} 12)(10)\end{array}$ \\
\hline 1370.2 & 25.6 & 1370.3 & $\mathrm{w}$ & 1367.7, 1366.2 & w & $\mathrm{A}^{\prime}$ & $\begin{array}{l}\delta(\mathrm{C} 2 \mathrm{C} 6 \mathrm{H} 9)(36)+v(\mathrm{C} 3-\mathrm{C} 4)(15)+\delta(\mathrm{C} 4-\mathrm{H} 11)(13)+ \\
v(\mathrm{C} 4=\mathrm{C} 5)(11)\end{array}$ \\
\hline 1091.9 & 35.5 & 1095.5 & W & 1094.9 & $\mathrm{w}$ & $\mathrm{A}^{\prime}$ & $v(\mathrm{C} 4=\mathrm{C} 5)(39)+\delta(\mathrm{C} 4-\mathrm{H} 11)(19)+v(\mathrm{C} 5-\mathrm{N} 1)$ \\
\hline 1030.8 & 41.9 & 1035.8 & $\mathrm{w}$ & 1031.7 & $\mathrm{w}$ & $\mathrm{A}^{\prime}$ & $\delta(\mathrm{C} 3-\mathrm{H} 10)(39)+v(\mathrm{C} 3-\mathrm{C} 4)(32)+\delta(\mathrm{C} 4-\mathrm{H} 11)(22)$ \\
\hline 981.3 & 0.01 & n.o. & & n.o. & & $\mathrm{A}^{\prime \prime}$ & $\gamma(\mathrm{H} 9-\mathrm{C} 6)(96)$ \\
\hline 959.3 & 0.8 & n.o. & & n.o. & & $\mathrm{A}^{\prime}$ & $\begin{array}{l}\delta(\mathrm{R} 1)(30)+v(\mathrm{C} 2=\mathrm{C} 3)(20)+v(\mathrm{~N} 1-\mathrm{C} 2)(17)+\delta(\mathrm{C} 4-\mathrm{H} 11) \\
(11)\end{array}$ \\
\hline 892.5 & 1.4 & n.o. & & n.o. & & $A^{\prime \prime}$ & $\gamma(\mathrm{CH}) \mathrm{R} 1(113)$ \\
\hline 876.4 & 7.5 & 881.8 & w & n.o. & & $A^{\prime}$ & $\delta(\mathrm{R} 2)(89)$ \\
\hline 819.7 & 17.0 & 820.5 & $\mathrm{w}$ & 825.5 & w & $\mathrm{A}^{\prime \prime}$ & $\gamma(\mathrm{CH}) \mathrm{R} 2(99)$ \\
\hline 740.0 & 64.9 & $748.5,747.2$ & $\mathrm{~m}$ & 745.0 & $\mathrm{~m}$ & $\mathrm{~A}^{\prime}$ & $\delta(\mathrm{C} 2 \mathrm{C} 6 \mathrm{O} 7)(36)+\delta(\mathrm{R} 1)(28)+v(\mathrm{C} 2-\mathrm{C} 6)(10)$ \\
\hline 733.6 & 79.4 & $\mathbf{7 4 2 . 4}, 741.4$ & $\mathrm{~m}$ & 740.0 & $\mathrm{~m}$ & $A^{\prime \prime}$ & $\gamma(\mathrm{CH}) \mathrm{R} 3(95)$ \\
\hline 630.6 & 14.9 & 635.3 & w & 638.9 & $\mathrm{w}$ & $A^{\prime \prime}$ & $\tau(\mathrm{R} 2)(86)+\tau(\mathrm{R} 1)$ \\
\hline 609.1 & 2.2 & n.o. & & n.o. & & $\mathrm{A}^{\prime \prime}$ & $\tau(\mathrm{R} 1)(97)+\tau(\mathrm{R} 2)(11)$ \\
\hline 492.6 & 73.1 & $509.6, \mathbf{5 0 8 . 8}, 506.8$ & $\mathrm{~m}$ & 518.8 & $\mathrm{~m}$ & $\mathrm{~A}^{\prime \prime}$ & $\gamma(\mathrm{N} 1-\mathrm{H} 8)(92)$ \\
\hline
\end{tabular}

${ }^{a}$ B3LYP/6-311++G(d,p)-calculated (scaled by a factor 0.978) wavenumbers and intensities are also given. ${ }^{a}$ Wavenumbers in $\mathrm{cm}^{-1}$, calculated intensities in $\mathrm{km} \mathrm{mol}{ }^{-1}$. $v$, bond stretching; $\delta$, bending; $\gamma$, rocking; $\tau$, torsion; w, wagging; tw, twisting; s, symmetric; as, antisymmetric; n.o., not observed; n.i., not investigated; w, weak; m, medium; S, strong; vS, very strong. ${ }^{b}$ PEDs lower than $10 \%$ are not included. Definition of symmetry coordinates is given in Table S1 (Supporting Information). See Figure 1 for atom numbering.

However, in xenon matrix, the spectroscopic results indicate that photochemical formation of the Dewar P2C valence isomer is suppressed. These observations are in agreement with the photochemistry of benzene in argon and xenon matrices. For benzene isolated in argon matrix, photochemical production of benzvalene, fulvene, and Dewar benzene valence isomers was reported, whereas no isomerization reactions were observed in xenon matrix. ${ }^{27}$ The additional photochemical channel in argon might then compete with the conformational isomerization and delay the establishment of the photostationary state.

A final comment on the conformational isomerization processes shall be made. After irradiation of the matrices, annealing experiments were carried out in order to verify if the photochemically formed trans conformer would convert back to the most stable cis form in the dark. The matrices were then annealed up to $30(\mathrm{Ar})$ or $60 \mathrm{~K}(\mathrm{Xe})$, but no conversion from the trans to the cis conformer was found to take place. This result confirms that once it is produced, the trans conformer is thermally stable in the matrix media (because the energy barrier for its conversion to the cis form is high enough, over $50 \mathrm{~kJ}$ $\mathrm{mol}^{-1}$, to preclude thermal isomerization). The fact that the trans form is stable in a matrix opens perspectives of successful experiments where the isomerization reactions can be induced by selective infrared excitation of the conformers and their relative amount in the matrix fully controlled in this way. Such experiments were recently carried out successfully in our laboratory for hydroxyacetone, ${ }^{28}$ where the barrier to the conformational isomerization is much lower (about $5 \mathrm{~kJ} \mathrm{~mol}^{-1}$ only) yet the photoproduced isomer is thermally stable.

Photolysis. Prolonged UV irradiation of the matrix-isolated $\mathrm{P} 2 \mathrm{C}$ leads to its decomposition into pyrrole and $\mathrm{CO}$. The photolytic decarbonylation was observed in both argon and xenon matrices but was more efficient in the latter. After ca. $120 \mathrm{~min}$ of irradiation $(\lambda>235 \mathrm{~nm})$ the photolysis consumed ca. $60 \%$ of the original reactant in argon matrix, while in xenon matrix ca. $90 \%$ of P2C was decomposed. This observed heavyatom effect on the photolysis suggests the participation of the $\mathrm{T}_{1}$ state in the process, which is well known to be involved in the $\alpha$ cleavage in ketones and aldehydes. ${ }^{29-32}$ Indeed, the photolysis of the compound after prolonged irradiation most probably occurs predominantly through homolytic cleavage of the $\mathrm{C} 2-\mathrm{C} 6$ bond in the $\mathrm{T}_{1}$ surface, after intersystem crossing following excitation to $S_{1}$. It has to be noted, instead, that the photoinduced conformational isomerization above discussed most probably occurs in the $S_{1}$ state or partially in the $S_{1}$ potential-energy surface with relaxation to the ground state 


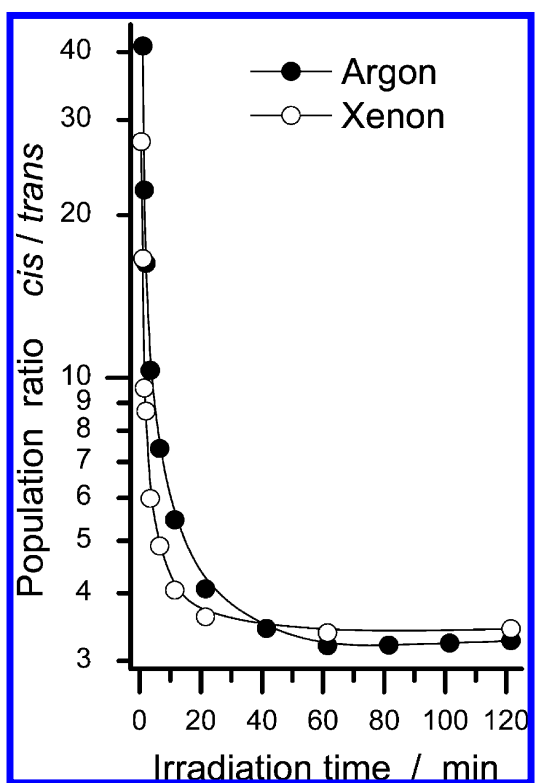

Figure 6. Population ratio of the two matrix-isolated $\mathrm{P} 2 \mathrm{C}$ conformers in the progress of UV irradiation $(\lambda>235 \mathrm{~nm})$ estimated from the intensities of the carbonyl stretching bands ascribed to the individual conformers. Integrated experimental absorptions were reduced by the calculated $v(\mathrm{C}=\mathrm{O})$ intensities.
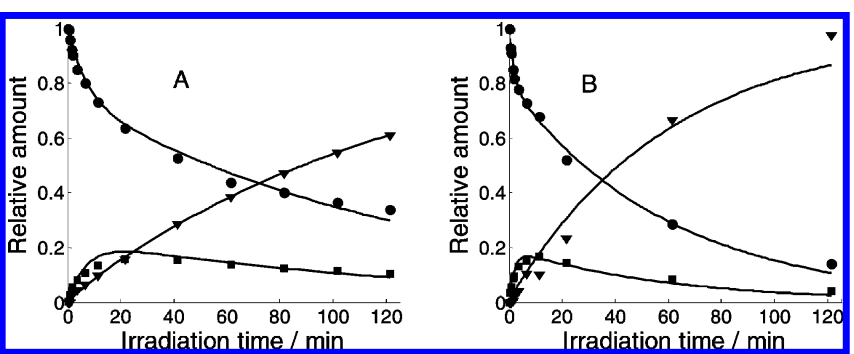

Figure 7. Evolution with time of irradiation of the relative amounts of cis-P2C ( $)$, trans-P2C $(\mathbf{\square})$, and carbon monoxide $(\boldsymbol{\nabla})$ in $\operatorname{argon}(\mathrm{A})$ and xenon (B) matrices. The experimental points were obtained from the intensities of the $v(\mathrm{C}=\mathrm{O})$ bands ascribed to the individual conformers of $\mathrm{P} 2 \mathrm{C}$ and carbon monoxide, reduced by the corresponding calculated intensities. In the plots, the initial amount of the cis form was normalized to unity. The curves were obtained by fitting kinetic model $b$ to the data points. Defining parameters of the curves and uncertainties in the parameters are given in the text.

through a conical intersection. This would account for the absence of the heavy-atom effect in the xenon matrix on the conformational isomerization yield and also for the insensitivity of this process to local matrix interactions already pointed out in the previous section.

The observed cis $\rightarrow$ trans isomerization starts from the very beginning of the irradiation and is much faster than the photodecomposition process, which started to be clearly observed only after $10 \mathrm{~min}$ of irradiation. The apparent lag time for observation of the photoproducts may be explained in several ways: (i) intrinsically weak intensities of pyrrole and $\mathrm{CO}$ absorptions hamper their experimental observation at the early stages; (ii) the probability of decomposition under the present irradiation conditions is much lower than for rotamerization; (iii) the requirement of initial production of the trans isomer, which would be the preferred reactant for decarbonylation. It shall be noted that these possibilities are mutually nonexclusive and may work in a synergetic way.

In order to understand the mechanism of isomerization/ decomposition processes, the experimental data were fitted using different kinetical models. These models were kept as simple
TABLE 7: Rate Constants $\left(\mathrm{min}^{-1}\right)$ Derived from the Fit of Data Obtained in Xenon and Argon Matrices During UV Irradiation

\begin{tabular}{cccc}
\hline model & $k_{1}$ & $k_{-1}$ & $k_{2}$ \\
\hline \multicolumn{4}{c}{ xenon matrix } \\
model $a$ & $0.103 \pm 0.031$ & $0.329 \pm 0.159$ & $0.089 \pm 0.016$ \\
model $b$ & $0.095 \pm 0.036$ & $0.414 \pm 0.200$ & $0.021 \pm 0.002$ \\
model $c$ & $0.094 \pm 0.033$ & $0.379 \pm 0.183$ & $0.017 \pm 0.002$ \\
\multicolumn{4}{c}{ argon matrix } \\
model $a$ & $0.047 \pm 0.011$ & $0.138 \pm 0.051$ & $0.0388 \pm 0.0048$ \\
model $b$ & $0.031 \pm 0.005$ & $0.108 \pm 0.021$ & $0.0100 \pm 0.0003$ \\
model $c$ & $0.033 \pm 0.006$ & $0.111 \pm 0.026$ & $0.0079 \pm 0.0003$
\end{tabular}

as possible, assuming only the conformational isomerization and the global photodecomposition process. The kinetic data used were the intensities of the $v \mathrm{C}=\mathrm{O}$ bands of cis- and trans- $\mathrm{P} 2 \mathrm{C}$ and that of the carbon monoxide, reduced by the corresponding calculated intensities and normalized for a unitary concentration of the initial reactant (cis). The following models were considered, where PP designates the photolysis products (pyrrole $+\mathrm{CO})$

$$
\text { cis } \underset{k_{1}}{\stackrel{k_{-1}}{\rightleftarrows}} \operatorname{trans} \stackrel{k_{2}}{\longrightarrow} \mathrm{PP}
$$

$$
\begin{gathered}
\text { cis } \underset{k_{1}}{\stackrel{k_{-1}}{\rightleftarrows} \operatorname{trans}} \\
\operatorname{cis} \stackrel{k_{2}}{\longrightarrow} \mathrm{PP} \\
\operatorname{cis} \underset{k_{1}}{\stackrel{k_{-1}}{\rightleftarrows}} \operatorname{trans} \stackrel{k_{2}}{\longrightarrow} \mathrm{PP} \\
\operatorname{cis} \stackrel{k_{2}}{\longrightarrow} \mathrm{PP}
\end{gathered}
$$

Models a and b imply that the decarbonylation reaction is conformer selective: a assumes that only the trans-P2C conformer undergoes significant photolysis to [pyrrole $+\mathrm{CO}$ ], while $\mathrm{b}$ assumes the same for the cis conformer. Model c assumes that both conformers can undergo decomposition under the current experimental conditions with equal probability. The fitting corresponding to model $\mathrm{b}$ is graphically represented in Figure 7.

For all three models tested, the derived differential equations were solved by numerical integration and fitted to the kinetic data using the MATLAB software package. ${ }^{31}$ The rate coefficients were used as fitting parameters. The obtained results are summarized in Table 7. Among the three models, model a results in rotamerization and decomposition constants of the same order of magnitude. This does not correspond to the experimental observation where the rotamerization is much faster. On this basis, model a should be rejected. Models b and c correspond better to the experimental observation: they predict constants for the decarbonylation process that are about 10 (Ar) or $20(\mathrm{Xe})$ times smaller than the rotamerization constants. As it could be expected, the heavy-atom effect taking place in the xenon matrix doubles the rate constant for the decarbonylation reaction in that matrix compared to argon. It is also worthy of note that the ratio of the rotamerization constants obtained in models $\mathrm{b}$ and $\mathrm{c}$ is close to the [cis]/[trans] ratio of 3.3 experimentally observed for the photostationary equilibrium, 


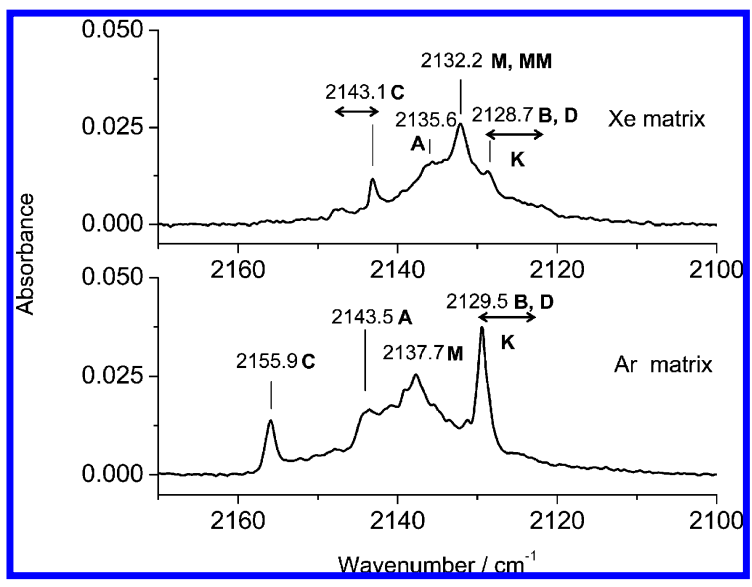

Figure 8. $v \mathrm{CO}$ stretching region of photolyzed argon and xenon $\mathrm{P} 2 \mathrm{C}$ matrices. The symbols A, B, C, and D refer to the pyrrole/carbon monoxide associates whose structures are presented in Figure 9 and energetic and vibrational calculated data given in Table 6. M designates the $\mathrm{CO}$ monomer, $\mathrm{MM}$ the $\mathrm{CO}$ dimer,and $\mathrm{K}$ the ketene species.

being 4.4 (model b) and 4.0 (model c) for xenon and 3.5 (model b) and 3.4 (model c) for argon.

It is difficult to choose between models $\mathrm{b}$ and $\mathrm{c}$ since they produce very similar results. Most probably, the present experiments cannot unequivocally answer the question as to which $\mathrm{P} 2 \mathrm{C}$ conformer (if any) gives origin to the decomposition reaction. One hypothesis that may explain why the kinetic models are not discriminative is the possibility of the occurrence of conformational isomerization in the excited electronic state, outside of the Franck-Condon region. To verify this hypothesis and understand better the photolysis mechanisms of P2C, further experiments with selective UV excitation of the chosen conformer (e.g., using laser irradiation) may be required.

Structural Characterization of the Pyrrole/CO Pairs Formed in the Matrices upon Photolysis. The assignment of the infrared bands of the photoproduced pyrrole has been made on the basis of work of Gómez-Zavaglia and Fausto. ${ }^{34}$ In particular, bands at 3533.3 (ascribable to $v \mathrm{NH}$ ) and 727.4, 724.9, and $723.0 \mathrm{~cm}^{-1}$ (assigned to the all-in-phase $\gamma \mathrm{CH}$ ) are visible in the argon matrix, while in xenon matrix the corresponding bands occur at 3502.1 and $3497.1(\nu \mathrm{NH})$ and $722.8 \mathrm{~cm}^{-1}(\gamma \mathrm{CH})$. The signature of $\mathrm{CO}$ is well known in both $\operatorname{argon}^{35-37}$ and xenon $^{36}$ matrices; it has been found to be quite sensitive to association and, specifically, to the type of association, which can be established by the molecule using both the carbon and the oxygen atoms as an electron donor ${ }^{37}$

Figure 8 shows the $2100-2170 \mathrm{~cm}^{-1}$ region of the spectra of the photolyzed argon and xenon matrices, where bands due to carbon monoxide absorb.

In argon, monomeric CO gives rise to a sharp intense band at $2138.5 \mathrm{~cm}^{-1}$ (nonrotating molecules) with a lower intensity shoulder at $2136.7 \mathrm{~cm}^{-1}$ (assigned to librating monomer molecules). ${ }^{35,37}$ Also, MP2 calculations are predicting CO dimers to absorb at frequencies very close to the main monomer band ${ }^{38}$ (there is no consensus in the literature about the preferred structure of the $\mathrm{CO}$ dimer; the potential-energy surface for this entity has been found to have several different almost-isoenergetic minima ${ }^{38}$ nevertheless, the most probable dimer geometry seems to be planar T-shaped connected by the oxygen or the carbon atoms, and both these forms were predicted to absorb at frequencies differing by less than $2 \mathrm{~cm}^{-1}$ from the position of the main monomer band). ${ }^{38}$ Experimentally, the well-isolated $\mathrm{CO}$ dimer has been proposed to absorb at $2140.1 \mathrm{~cm}^{-1}$ in argon matrix. ${ }^{36}$ In xenon matrix, well-isolated monomer absorbs at

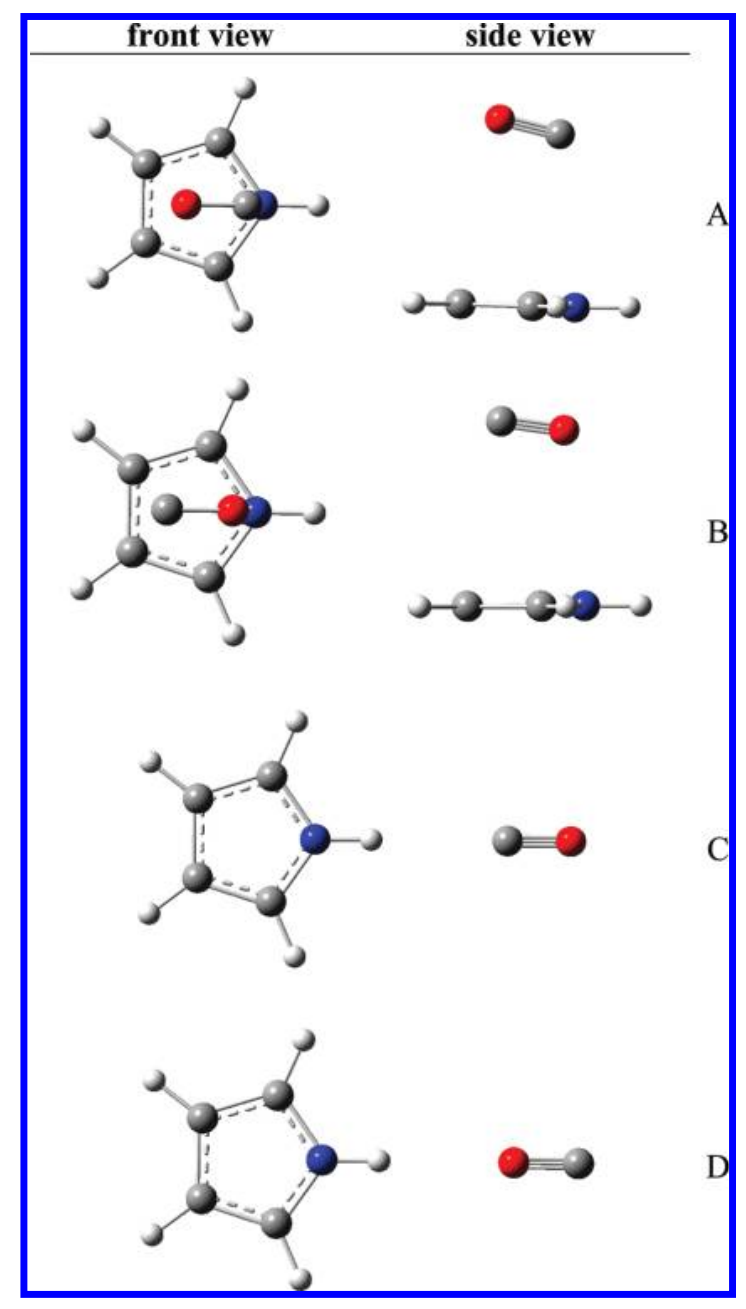

Figure 9. MP2/6-311++G(d,p)-calculated structures for pyrrole/carbon monoxide dimer (see Table 6 for details).

2132.9 (nonrotating molecules) and $2133.1 \mathrm{~cm}^{-1}$ (librating molecules) ${ }^{36}$ and the dimer at $2133.7 \mathrm{~cm}^{-1} .36$

The spectra of the photolyzed matrices obtained in the present study show, in the $2100-2170 \mathrm{~cm}^{-1}$ range, profiles that strongly differ from those observed in the spectra of matrix-isolated monomeric $\mathrm{CO}$. In the argon matrix, four bands were observed at $2155.9,2143.5,2137.7$, and $2129.5 \mathrm{~cm}^{-1}$, the latter band being the most intense, while in the xenon matrix a broad structured feature was observed, with absolute maximum at $2132.2 \mathrm{~cm}^{-1}$ and main relative maxima at 2143.1, 2135.6, and $2128.7 \mathrm{~cm}^{-1}$ (Figure 8). The observed profiles are in agreement with prevalent complexation of $\mathrm{CO}$ with pyrrole formed in the same matrix cage after photodecomposition of P2C.

In an attempt to elucidate the structures of the pyrrole/carbon monoxide associates which are dominant in the two different types of matrices, the structures of the possible associates and their IR spectra were calculated at the MP2/6-311++G(d,p) level of theory. The use, in these calculations, of the MP2 method instead of the DFT/B3LYP approach was determined by the well-known better performance of the first method in dealing with noncovalently bonded species. ${ }^{39}$ The relevant energy and vibrational data are presented in Table 8, and the structures of the associates are shown in Figure 9.

The main conclusions from Table 8 and Figure 9 can be summarized as follows: (i) Four pyrrole/carbon monoxide complexes were theoretically tested with binding energies ranging from ca. 4.7 to ca. $8.3 \mathrm{~kJ} \mathrm{~mol}^{-1}$. (ii) The most stable associate was predicted to be the stacked structure where the 
TABLE 8: MP2/6-311++G(d,p)-Calculated Energies and $\boldsymbol{v C O}$ Vibrational Frequencies and Infrared Intensities of Pyrrole/ Carbon Monoxide Associates

\begin{tabular}{|c|c|c|c|c|c|c|}
\hline & species $^{b}$ & $\begin{array}{l}E \text {, total energy } \\
(0 \mathrm{~K}) / \text { hartree }\end{array}$ & $\begin{array}{c}\Delta E, \text { binding } \\
\text { energy } / \mathrm{kJ} \mathrm{mol}^{-1}\end{array}$ & $\begin{array}{c}\Delta E(\mathrm{X}-\mathrm{A}),{ }^{a} \text { relative } \\
\text { energy of associates } / \mathrm{kJ} \mathrm{mol}^{-1}\end{array}$ & $\begin{array}{c}\nu \mathrm{CO}, \\
\text { wavenumber/cm } \\
-1\end{array}$ & $\begin{array}{l}\nu \mathrm{CO}, \text { IR intensity/ } \\
\mathrm{km} \mathrm{mol}^{-1}\end{array}$ \\
\hline A & stacked pyrrole/CO & -322.596962 & -8.28 & 0.00 & 2122.86 & 24.8 \\
\hline B & stacked pyrrole/OC & -322.596774 & -7.79 & 0.49 & 2116.23 & 27.9 \\
\hline \multirow[t]{3}{*}{$\mathrm{D}$} & pyrrole-NH/OC & -322.595598 & -4.70 & 3.58 & 2118.70 & 60.1 \\
\hline & pyrrole + CO & -322.593808 & 0.00 & & & \\
\hline & pyrrole & -209.520478 & & & & \\
\hline
\end{tabular}

$\mathrm{CO}$ molecule is placed parallel to the pyrrole ring with the carbon atom pointing to the $\mathrm{N}$ pyrrole atom (form $\mathrm{A}$ ), in agreement with the experimental data obtained by microwave spectroscopy. ${ }^{40}$ (iii) The second most stable associate is predicted to be the structure analogous to the most stable one but with the $\mathrm{CO}$ molecule oriented in such a way that the oxygen atom is closer to the pyrrole heteroatom (form $\mathrm{B}$ ). The energies of $\mathrm{A}$ and $\mathrm{B}$ are very similar $\left[\Delta E(\mathrm{~B}-\mathrm{A})=0.49 \mathrm{~kJ} \mathrm{~mol}^{-1}\right]$. (iv) The associates where the $\mathrm{CO}$ molecule is hydrogen-bonded to the $\mathrm{N}-\mathrm{H}$ moiety of the pyrrole (C and D) were found to be less stable than the two stacked structures. (v) The $\mathrm{NH} \cdots \mathrm{CO}$ associate (form $\mathrm{C}$ ) was predicted to give rise to a $v \mathrm{CO}$ stretching band blue-shifted by ca. $13 \mathrm{~cm}^{-1}$ in relation to that of the monomeric $\mathrm{CO}$, whereas the $\mathrm{NH} \cdots \mathrm{OC}$ associate (form D) was predicted to give rise to a red-shifted $v \mathrm{CO}$ stretching (by 5 $\mathrm{cm}^{-1}$ ). These trends are in agreement with those found by Lundell et al. ${ }^{37}$ in relation to $\mathrm{NH}_{3} / \mathrm{CO}$ and $\mathrm{NH}_{3} / \mathrm{OC}$ associates, i.e., complexes in which the $\mathrm{CO}$ molecule is oxygen-bonded with the $\mathrm{NH}$-partner molecule have $v \mathrm{CO}$ frequencies red-shifted with respect to the monomer while in the case of carbon-bonded complexes the absorption bands are blue-shifted. (vi) In the case of the stacked associates, the most stable form (A) was predicted to give rise to a $\nu \mathrm{CO}$ stretching band nearly at the same position as the $\mathrm{CO}$ monomer and $\mathrm{B}$ to a band red-shifted band by a similar amount as form D.

Taking into account the results of the theoretical calculations, it can then be concluded that in the photolyzed argon matrix the predominant associates are the pyrrole- $\mathrm{NH} /$ carbon monoxide form $\mathrm{C}$, which gives rise to the band at $2155.9 \mathrm{~cm}^{-1}$, and the most stable stacked associate (A), absorbing in the frequency range $2145-2130 \mathrm{~cm}^{-1}$ (see Figure 8). The driving of the CO molecule to above the pyrrole ring (to form the stacked associates) can be expected to require considerably more energy than that required to form the planar associates, $\mathrm{C}$ and $\mathrm{D}$ (see Table 8). This means that the formation of the $\mathrm{C}$ associate is facilitated by the cage confinement of the photolytic process in the matrix. The band at $2129.5 \mathrm{~cm}^{-1}$ could be, in principle, ascribed to the formation of either D or B associates, and they probably contribute partially to the observed multiplet band depicted in Figure 8. However, a band at this frequency may also be due to the antisymmetric stretching vibration of a ketene moiety $(\nu \mathrm{C}=\mathrm{C}=\mathrm{O})$. UV-induced generation of ketene photoproducts has already been observed previously for such systems as benzenedicarbaldehydes ${ }^{11}$ or $\alpha, \beta$-unsaturated heterocycles. ${ }^{41}$ In the case of $\mathrm{P} 2 \mathrm{C}$, a ketene-containing photoproduct can be generated as well, and its calculated structure and vibrational spectrum are presented in Table S1 and Figure S1 (Supporting Information). The calculation predicts that the $\nu \mathrm{C}=\mathrm{C}=\mathrm{O}$ band of the ketene photoproduct (K, Figure 8) appears ca. $9 \mathrm{~cm}^{-1}$ downshifted in relation to that due to the carbon monoxide monomer (M, Figure 8), exactly as observed in the experiment.
The infrared intensity of the ketene photoproduct $\nu \mathrm{C}=\mathrm{C}=\mathrm{O}$ vibration is predicted to be 1 order of magnitude higher (ca. $733 \mathrm{~km} \mathrm{~mol}^{-1}$ ) than that of the carbon monoxide band (ca. 89 $\mathrm{km} \mathrm{mol}^{-1}$ ). Since the experimental integrated absorptions of all features in 2200-2100 $\mathrm{cm}^{-1}$ region (Figure 8) are approximately equal, it can be deduced that the ketene (although still detectable spectroscopically) is present in trace amounts in the photolyzed matrix. Therefore, its production does not interfere with kinetic mechanism discussed above. Moreover, the $\nu \mathrm{C}=\mathrm{C}=\mathrm{O}$ band is by far the most intense band of the ketene, so that no other bands ascribable to this species could be observed.

The ability of CO to escape from the matrix cage in which it was formed in the argon matrix can be stated to be rather reduced, since the band due to monomeric CO (at ca. 2139 $\mathrm{cm}^{-1}$ ) shows a very little intensity.

In the xenon matrix, the results show a different pattern, which is in agreement with higher mobility of the CO molecules in this medium. Most of the intensity of the feature observed in the $v \mathrm{CO}$ stretching region in this matrix occurs for a frequency range $\left(2128-2137 \mathrm{~cm}^{-1}\right)$ that can be ascribed both to monomeric (or dimeric) $\mathrm{CO}$ and the stacked pyrrole/carbon monoxide most stable associate (A). The presence of the pyrrole$\mathrm{NH} /$ carbon monoxide form $(\mathrm{C})$ in the xenon photolyzed matrix is accounted for by the band at $2143 \mathrm{~cm}^{-1}$ (see Figure 8) and seems to be slightly less intense in comparison with the argon matrix.

Hence, the results indicate that in the xenon matrix, once formed by photolysis of $\mathrm{P} 2 \mathrm{C}$, the $\mathrm{CO}$ molecule shows an increased mobility, leading to the predominant formation of the most stable associate, A. The absorption at lower frequencies observed in the argon matrix and assigned to the presence of a ketene isomer of $\mathrm{P} 2 \mathrm{C}$ is practically absent in the photolyzed xenon matrix. This fact points out the reduced importance of the isomerization process in xenon leading to ketene production.

\section{Conclusions}

The molecular structures of the two conformers of P2C, their vibrational spectra, and the UV-induced photochemistry of the compound were studied using the method of low-temperature matrix isolation combined with infrared spectroscopy. Interpretation of the experimental data received support from quantum chemical calculations performed at both the DFT and the MP2 levels of approximation as well as from natural bond orbital analysis.

It was found that UV $(\lambda>235 \mathrm{~nm})$ irradiation of the matrixisolated P2C promotes internal rotation of the aldehyde group, leading to isomerization of the conformational ground state (cis) into the less stable conformer (trans). To the best of our knowledge, the trans form was experimentally observed and 
characterized for the first time. Prolonged UV irradiation of the matrix led to photodetachment of carbon monoxide with simultaneous formation of pyrrole. In the matrices, $\mathrm{CO}$ and pyrrole formed in the same matrix cage were found to be predominantly associated, the amount of different dimeric structures depending on the matrix type.

Acknowledgment. The authors thank Drs. Mika Petterson and Jan Lundell (Department of Chemistry, University of Jyväskylä, Finland) for their helpful discussions during the Matrix Isolation Gordon Research Conference (Oxford, July 2009). This work was supported by FCT (Project PTDC/QUI/ 71203/2006). The authors also thank FCT (Portugal) and CNRS (Italy) by having awarded a joint Coimbra-Bologna collaborative grant. B.M.G. acknowledges FCT for the postdoctoral grant (ref. SFRH/BPD/44689/2008).

Supporting Information Available: Optimized geometries for cis and trans isomers of pyrrole-2-carbaldehyde and ketene photoproduct calculated at the B3LYP/6-311++G(d,p) level, internal coordinates used in the normal modes analysis for the cis and trans isomers, and calculated B3LYP/6-311++G(d,p) infrared spectrum of monomeric ketene photoproduct compared with the calculated infrared absorption of carbon monoxide. This material is available free of charge via the Internet at http:// pubs.acs.org.

\section{References and Notes}

(1) Fischer, H.; Gleim, W. Justus Liebig's Ann. Chem. 1935, 521, 157.

(2) Wiehe, A.; Ryppa, C.; Senge, M. O. Org. Lett. 2002, 4, 3807. 134313

(3) Rice, C. A.; Dauster, I.; Suhm, M. A. J. Chem. Phvs. 2007, 126,

(4) Marstokk, K. M.; Møllendal, A. H. J. Mol. Struct. 1974, 23, 93.

(5) Dubis, A. T.; Grabowski, S. J. J. Phvs. Chem. A 2003, 107, 8723.

(6) Farnier, M.; Drakenberg, T. J. Chem. Soc. Perkin Trans. 21975 333.

(7) Kaye, P. T.; Macrae, R.; Meakins, G. D.; Patterson, C. H. Chem. Soc. Perkin Trans. 2 1980, 1631.

(8) John, I. G.; Ritchie, G. L. D.; Radom., L. J. Chem. Soc. Perkin Trans. 2 1977, 1601.

(9) Itoh, T. Chem. Phvs. Lett. 2008, 466, 141.

(10) Ohno, K.; Itoh, T.; Yokota, C.; Katsumoto, Y. J. Mol. Struct. 2006 $825,143$.

(11) Ohno, K.; Itoh, T. J. Phys. Chem. A 2007, 111, 7048

(12) Frisch, M. J.; Trucks, G. W.; Schlegel, H. B.; Scuseria, G. E.; Robb, M. A.; Cheeseman, J. R.; Montgomery, J., J. A.; Vreven, T.; Kudin, K. N.; Burant, J. C.; Millam, J. M.; Iyengar, S. S.; Tomasi, J.; Barone, V.; Mennucci, B.; Cossi, M.; Scalmani, G.; Rega, N.; Petersson, G. A.; Nakatsuji, H.; Hada, M.; Ehara, M.; Toyota, K.; Fukuda, R.; Hasegawa, J.; Ishida, M.; Nakajima, T.; Honda, Y.; Kitao, O.; Nakai, H.; Klene, M.; Li, X.; Knox, J. E.; Hratchian, H. P.; Cross, J. B.; Bakken, V.; Adamo, C.; Jaramillo, J.; Gomperts, R.; Stratmann, R. E.; Yazyev, O.; Austin, A. J.; Cammi, R.; Pomelli, C.; Ochterski, J. W.; Ayala, P. Y.; Morokuma, K.; Voth, G. A.; Salvador, P.; Dannenberg, J. J.; Zakrzewski, V. G.; Dapprich, S.; Daniels, A. D.; Strain, M. C.; Farkas, O.; Malick, D. K.; Rabuck, A. D.;
Raghavachari, K.; Foresman, J. B.; Ortiz, J. V.; Cui, Q.; Baboul, A. G.; Clifford, S.; Cioslowski, J.; Stefanov, B. B.; Liu, G.; Liashenko, A.; Piskorz, P.; Komaromi, I.; Martin, R. L.; Fox, D. J.; Keith, T.; Al-Laham, M. A.; Peng, C. Y.; Nanayakkara, A.; Challacombe, M.; Gill, P. M. W.; Johnson, B.; Chen, W.; Wong, M. W.; Gonzalez, C.; Pople, J. A. Gaussian 03, Revision C.02 ed.; Gaussian, Inc.: Wallingford, CT, 2004.

(13) Frisch, M.; Head-Gordon, M.; Pople, J. Chem. Phvs. Lett. 1990, 166, 281.

(14) Becke, A. Phvs. Rev. A 1988, 38, 3098.

(15) Lee, C.; Yang, W.; Parr, R. Phvs. Rev. B 1988, 37, 785

(16) Peng, C.; Schlegel, H. B. Isr. J. Chem. 1994, 33, 449.

(17) Schachtschneider, J. H.; Mortimer, F. S. Vibrational Analysis of Polyatomic Molecules. VI. FORTRAN IV Programs for Solving the Vibrational Secular Equation and for the Least-Squares Refinement of Force Constants; Project No. 31450, Structural Interpretation of Spectra; Shell Development Co.: 1969

(18) Pulay, P.; Fogarasi, G.; Pang, F.; Boggs, J. E. J. Am. Chem. Soc. 1979, 110,2550

(19) Cioslowski, J. J. Am. Chem. Soc. 1989, 111, 8333.

(20) Weinhold, F.; Landis, C. R. Valency and Bonding. A Natural Bond Orbital Donor-Acceptor Perspective; Cambridge University Press: New York, 2005.

(21) Reed, A. E.; Curtiss, L. A.; Weinhold, F. Chem. Rev. 1988, 88, 899.

(22) The NBO and APT charges shown in Table 1 generally show the same trends, though their absolute values might in the same cases differ considerably. It is known, for example, that $\mathrm{C}-\mathrm{H}$ bond dipoles are overestimated by the NBO method, see ref

(23) Freeman, F.; Lau, D. J.; Patel, A. R.; Pavia, P. R.; Willey, J. D. J. Phvs. Chem. A 2008, 112, 8775.

(24) Fausto, R.; Batista de Carvalho, L. A. E.; Teixeira-Dias, J. J. C.; Ramos, M. N. J. Chem. Soc. Faradav Trans. 2 1989, 85, 1945.

(25) McKean, D. C. Chem. Soc. Rev. 1978, 7, 399.

(26) Castiglioni, C.; Gussoni, M.; Zerbi, G. J. Chem. Phvs. 1985, 82, 3534.

(27) Johnstone, D. E.; Sodeau, J. R. J. Phvs. Chem. 1991, 95, 165.

(28) Sharma, A.; Reva, I.; Fausto, R. J. Am. Chem. Soc. 2009, 131, 8752 .

(29) Kossanyi, J.; Sabbah, S.; Chaquin, P.; Ronfart-Haret, J. C. Tetrahedron 1981, 37, 3307.

(30) Yadav, J. S.; Goddard, J. J. Chem. Phys. 1986, 84, 2682.

(31) Horowitz, A.; Kershner, C. J.; Calvert, J. J. Phvs. Chem. 1982, 86, 3094.

(32) Diau, E. W.-G.; Kötting, C.; Zewail, A. H. ChemPhysChem 2001, $2,273$.

(33) MATLAB, version 7.3.0.267 (R2006b); The MathWorks, Inc.: Natick, MA, 1994-2006; see www.mathworks.com/patents.

(34) Gómez-Zavaglia, A.; Fausto, R. J. Phvs. Chem. A 2004, 108, 6953.

(35) Maki, A. G. J. Chem. Phvs. 1961, 35, 931.

(36) Abe, H.; Yamada, K. M. T. Struct. Chem. 2003, 14, 211, and references therein.

(37) Lundell, J.; Krajewska, M.; Räsänen, M. J. Mol. Struct. 1998, 448, 221.

(38) Nxumalo, L. N.; Ngidi, E. K.; Ford, T. A. J.Mol. Struct. 2006, $786,168$.

(39) Lee, E. C.; Kim, D.; Jurecka, P.; Tarakeshwar, P.; Hobza, P.; Kim, K. S. J. Phys. Chem. A 2007, 111, 3446.

(40) Bettens, R. P. A.; Huber, S. R.; Bauder, A. J. Phvs. Chem. 1994, 98,4551 .

(41) Breda, S.; Reva, I.; Lapinski, L.; Fausto, R. Phys. Chem. Chem. Phvs. 2004, 6, 929.

JP911118V 